\title{
Tafonomía lítica del sitio Quebrada de Quereo: abordando el problema de la ambigüedad antropogénica en contextos del final del Pleistoceno
}

\author{
Lithic taphonomy of the Quebrada de Quereo site: addressing the \\ problem of anthropogenic ambiguity in Late Pleistocene assemblages
}

\author{
Javier Carranza ${ }^{1}$ https://orcid.org/0000-0003-3746-5621 \\ César Méndez ${ }^{2}$ https://orcid.org/ 0000-0003-2735-7950 \\ ${ }^{1}$ Investigador asociado a Fondecyt 1180306. \\ javier.carranza.elola@gmail.com \\ ${ }^{2}$ Centro de Investigación en Ecosistemas de la Patagonia. Coyhaique, CHILE. \\ cesar.mendez@ciep.cl
}

\section{Resumen}

Este artículo busca desarrollar una propuesta de análisis para enfrentar la ambigüedad en material lítico en contextos finipleistocenos de localidades aluviales. Enfocamos nuestro estudio en el sitio Quebrada de Quereo (13.480-13.070 cal AP), ubicado en la costa del norte semiárido de Chile. Como una manera de construir un análogo con fines comparativos, se exploraron diferentes combinaciones de variables tafonómicas y tecnológicas en un conjunto de origen natural levantado en una quebrada cercana que emula atributos técnicos de rocas talladas. El mismo conjunto de variables fue probado en el conjunto lítico de origen antropogénico del sitio Quebrada Santa Julia (12.990-12.730 cal AP). Este procedimiento nos permitió desarrollar un sistema de clasificación centrado en las características de los bordes astillados para sopesar atributos tafonómicos y tecnológicos y su producción natural en contextos de quebradas torrenciales. Aplicando este esquema a una muestra del conjunto lítico de Quebrada de Quereo, discutimos qué piezas tienen mayores probabilidades de ser consideradas como artefactos líticos. Se concluye que una parte importante del conjunto lítico del sitio Quebrada de Quereo puede ser explicado por causas naturales, por lo tanto, esas piezas deberían ser consideradas como pseudoartefactos.

Palabras claves: tafonomía lítica, norte semiárido, Pleistoceno Tardío, pseudoartefactos, ambigüedad antropogénica.

\begin{abstract}
This paper aims to develop an analytical proposal for dealing with ambiguity in lithic material of late Pleistocene contexts in alluvial locations. We focus our study on the Quebrada de Quereo site (13480-13070 cal BP) located in the coast of Northern Semiarid Chile. To build a comparative analog, different combinations of taphonomic and technological variables are explored in an assemblage of natural origin from a nearby ravine that mimics lithic knapping attributes. This same set of variables was tested on the anthropogenic lithic assemblage of the Quebrada Santa Julia site (12990-12730 cal BP). This procedure allowed us developing an analytic system centered on the characteristics of chipped edges to weigh taphonomic and technological attributes and their natural production in torrential ravine contexts. By applying this scheme to a sample of the lithic material of Quebrada de Quereo, we discuss which pieces are most likely to be considered as lithic artifacts. We conclude that most of the Quebrada de Quereo lithic assemblage may be explained as produced by natural causes, thus those pieces should be considered pseudo-artifacts.
\end{abstract}

Keywords: lithic taphonomy, semiarid north, late Pleistocene, pseudo-artifacts, anthropogenic ambiguity.

Recibido: 10 julio 2018. Aceptado: 26 junio 2019 


\section{Introducción}

En Sudamérica, durante los últimos años, el problema de la ambigüedad antropogénica en contextos tempranos ha sido discutida en sitios con conjuntos líticos escasos y/o poco diagnósticos o bien en aquellos con abundantes especímenes, pero cuyos atributos morfológicos son de difícil lectura debido a las posibilidades de equifinalidad con agentes naturales que pudieron producirlos (Guidon y Arnaud, 1991; Guidon, Pessis, Parenti, Fontugue y Guérin, 1996; Guidon, 2008; Boëda et al., 2014; Farińa et al., 2014a; 2014b; Suárez et al., 2014; Prentiss, Walsh, Barnett, Murphy y Kuenstle, 2015; Garvey y Mena, 2016). En la medida que un contexto arqueológico es más antiguo, el escrutinio respecto a la cualidad cultural de sus evidencias se vuelve mucho más incisivo, en tanto se supone que una mayor cantidad y diversidad de agentes pueden haber influido en cómo se nos presentan (Proffitt et al., 2016; Fiedel, 2017).

Más allá de intentar zanjar un problema que desde los orígenes de la arqueología resurge cada cierto tiempo (Warren, 1905; Ascher y Ascher, 1965; Haynes, 1973; Méndez, 2015; Borrero, 2016), en este trabajo se intenta generar una propuesta de análisis para sopesar el efecto de la meteorización de las rocas frente a la talla lítica intencionada. Buscamos abordar el problema de la ambigüedad antropogénica sobre la presunción de que todas las rocas sufren alteraciones tafonómicas al formar parte de un depósito como partícula sedimentaria (Schiffer, 1983; Hiscock, 1985; Stein, 1987; Borrazzo, 2006; Goldberg y Macphail, 2006), lo cual implica abordar los datos tafonómicos como una manera de reducir esta ambigüedad (Borrero, 2016).

El sitio Quebrada de Quereo (QQ), en el norte semiárido de Chile (comuna de Los Vilos, región de Coquimbo), fue estudiado en las décadas de 1980 y 1990 (Núñez, Varela y Casamiquela, 1983, 1987; Núñez, Varela, Casamiquela y Villagrán, 1994). Presenta fechas que enmarcan sus conjuntos arqueológicos entre 13.470 y 13.270 ańos cal AP en el caso del nivel Quereo I y de 12.980 ańos cal AP en el caso del nivel Quereo II (Núñez et al., 1994; Méndez, 2015). El contexto expuso restos óseos de un variado elenco faunístico de grandes mamíferos herbívoros extintos que, sin embargo, están asociados a un conjunto lítico ambiguo (Núnez et al., 1994; López, Labarca y Núñez, 2004; Méndez, 2015). De acuerdo con la geología local, las piezas líticas habrían sido escogidas entre rocas disponibles en las inmediaciones del sitio para ser utilizadas directamente en labores de procesamiento de fauna (Núñez et al., 1994). El conjunto lítico consiste principalmente en clastos de microdiorita/diabasa de forma "laminar" cuya forma y ángulo del borde permitieron definir tres categorías: "litos con acciones de raspado y raido", "litos con acciones de corte" y "fragmentos laminares con muescas" (Núñez et al., 1983, pp. 48-50). Sin embargo, la fragilidad de los bordes de estas piezas llamó la atención respecto a la posibilidad de que agentes naturales pudieran haber intervenido en su modificación (Méndez, 2015).

En este trabajo se realizó un escrutinio tafonómico para poner a prueba los atributos morfológicos que han permitido sustentar el argumento de la manufactura humana de estas piezas. Utilizando como base analítica una muestra del conjunto lítico de un sitio cercano -Quebrada Santa Julia (Jackson, Méndez, Seguel, Maldonado y Vargas, 2007; Méndez, 2015, Méndez y Jackson, 2015)-, así como un conjunto lítico obtenido en un muestreo actualístico de rocas naturales en la cuenca de la quebrada donde se emplaza este sitio, planteamos una serie de procesos tafonómicos que permitirían explicar buena parte de la diversidad morfológica del conjunto lítico de QQ, discutiendo su origen humano.

La ambigüedad antropogénica a nivel de tecnología lítica es un problema interpretativo que consiste en la dificultad o imposibilidad para distinguir los efectos del trabajo humano de los efectos de la meteorización de las rocas. Llamamos pseudoartefactos o geofactos a las rocas que exhiben una serie de rasgos en apariencia tecnológicos, pero cuyo origen se encuentra en procesos fundamentalmente geológicos. Este tipo de piezas, en su condición de rocas alteradas mecánica y químicamente por agentes naturales, necesariamente reflejarán en sus atributos morfológicos las energías formadoras de los depósitos en los que se encuentran. Al estar ausente la intencionalidad humana, sus cicatrices mostrarán una profusión poco económica y una carencia 
de "diseño lógico" (Oakley, 1968; Haynes, 1973; O'Connor, 2007). Sin embargo, desde el punto de vista del investigador, los pseudoartefactos presentan lo que podríamos denominar "atributos mínimos de funcionalidad”, es decir, rasgos mínimos para configurar una pieza funcionalmente aceptable como los atributos típicos de las lascas, las características de los bordes astillados, la ergonomía de los bordes pasivos en relación con el supuesto borde activo de la pieza, entre otros rasgos morfológicos (Ellen y Muthana, 2010). Un enfoque de tafonomía lítica (Hiscock, 1985; Borrazzo, 2006; Eren, Boehm, Morgan, Anderson y Andrews, 2011; Balirán, 2014) es útil para nuestro problema, ya que al centrarse en los agentes y efectos de la alteración de las rocas pone en su foco el proceso de meteorización y cómo este influye en nuestra percepción del registro arqueológico.

\section{Área de estudio y el sitio Quebrada de Quereo}

El área de estudio se encuentra en la comuna de Los Vilos, emplazada en la costa del norte semiárido de Chile. Presenta un clima mediterráneo costero que favorece el desarrollo del bosque esclerófilo en los sectores más húmedos, contrastando con las formaciones vegetales xerofíticas dominantes típicas del clima semiárido que se observan en las planicies litorales lejanas a cursos de agua y sobre los sectores de dunas (Luebert y Pliscoff, 2006). Geomorfológicamente, la zona está determinada por la presencia de la cordillera de la Costa, desde la cual descienden en sentido E-O quebradas como las de Mal Paso, El Negro, El Boldo y los afluentes del estero de Quereo que observamos en el área de estudio (Figura 1).

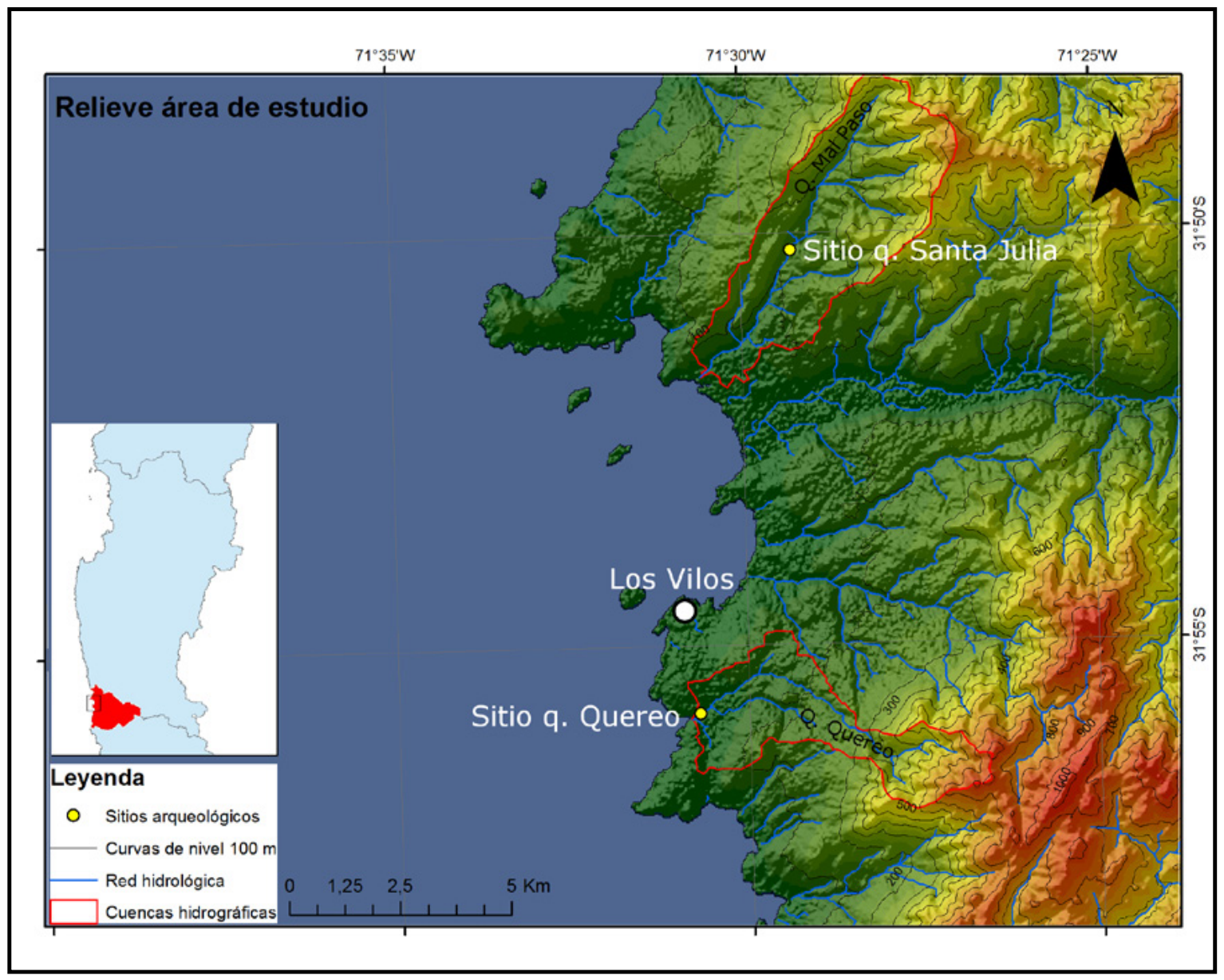

Figura 1. Mapa de relieve área de Los Vilos, cuencas hidrográficas y emplazamientos de los sitios considerados en el estudio. 
La quebrada de Quereo y otros lugares considerados en este trabajo se emplazan en la planicie litoral de Los Vilos, en donde fenómenos de carácter oceánico han modelado un relieve marcado por terrazas marinas de abrasión, a la vez que la tectónica ha conformado rasgos estructurales como fallas y grabenes (Varela, 1981; Núñez et al., 1987). Las principales formaciones geológicas de nuestra área de estudio son:

- Formación El Quereo: rocas sedimentarias como conglomerados, brechas, areniscas y lutitas (Cecioni y Westermann, 1968).

- Formación El Arrayán, secuencia marina transicional compuesta de areniscas y pelitas, que en la zona de Los Vilos está afectada por un metamorfismo epizonal, presentando pizarras filíticas (Rivano y Sepúlveda, 1991).

- Formación Pichidangui: rocas volcánicas como brechas volcánicas, tobas y lavas riolíticas, con algunas intercalaciones lutíticas (Cecioni y Westermann, 1968; Vicente, 1974).

- Granitos de la Unidad Tranquila (Rivano y Sepúlveda, 1991).

Entre la formación El Quereo y El Arrayán se observa una discordancia angular y de erosión, en la que el contacto está cortado por un dique diabásico. Este cuerpo intrusivo aflora en la desembocadura de la quebrada de Quereo, desde la cual se habrían obtenido las materias primas representadas en los niveles Pleistocenos del sitio homónimo (Núñez et al., 1994).

El sitio Quebrada de Quereo se emplaza al interior de una quebrada de escurrimiento hacia el océano, sobre su perfil sur, próximo a su desembocadura $(-125 \mathrm{~m})$. Corresponde a un contexto estratigráfico en el que sucesivas unidades aluviales superpuestas acusan de forma compactada la sucesión de eventos de génesis palustre del Graben Central (Varela, 1981; Núńez et al., 1994), en torno al cual existen abundantes evidencias de fauna extinta de finales del Pleistoceno (Méndez, Jackson y Seguel, 2004; López, 2007). El sitio se encuentra asociado a un bosque de carácter "relicto". Este tipo de bosques son alimentados por aguas subterráneas que nacen desde la cordillera de la Costa y afloran próximas a sus desembocaduras (Maldonado et al., 2010). El escurrimiento es intermitente y ocasionalmente torrencial. La estratigrafía de este sitio ha sido previamente publicada y discutida extensamente (Varela, 1981; Núñez et al., 1987, 1994). La sección excavada expuso un total de seis miembros estratigráficos principales, subdivididos en capas horizontales y subhorizontales superpuestas y ordenadas, que se enmarcan entre $>13.474 \mathrm{y}-\mathrm{al}$ menoslos 2500 ańos cal AP, edad límite para el fin de la incorporación de sedimentos e inicio de la incisión y formación de la quebrada, como se observa en la actualidad (Núñez et al., 1994; Méndez, 2015).

\section{Muestra}

La construcción de referentes comparativos de origen natural y antropogénico es una estrategia común en los estudios relacionados con la problemática de los pseudoartefactos (p.e., Hiscock, 1985; Petraglia y Potts, 1994; Burroni, Donahue y Pollard, 2002; Borrazzo, 2006, 2011, 2016; Lopinot y Ray, 2007). Siguiendo esta lógica, seleccionamos un referente arqueológico de similares características a QQ: el sitio Quebrada Santa Julia (QSJ), el cual presenta un contexto en estratigrafía donde restos de fauna extinta están asociados a artefactos líticos de origen antropogénico entre 13.070 - 12.740 y 12.970 12.680 cal AP (Jackson et al., 2007; Méndez, 2015; Méndez y Jackson, 2015). Sobre una muestra de este conjunto, realizamos un análisis tafonómico para identificar efectos de agentes naturales en un contexto estratigráfico de similares características de los depósitos finipleistocenos de QQ.

La quebrada Mal Paso, lugar donde se encuentra QSJ, ofrece además la posibilidad de explorar cómo se producen de manera natural atributos en bordes de piezas líticas que pueden ser interpretados como rasgos tecnológicos. Para esto, realizamos un muestreo actualístico superficial para interpretar, a partir de rasgos tafonómicos, los procesos que modificaron sus atributos morfológicos. Esta quebrada tiene en común con la quebrada de Quereo sus depósitos en sistemas hidrológicos de corta extensión (en torno a los $8 \mathrm{~km}$ ) que nacen de la cordillera de la Costa y desembocan directamente en el mar. En ambas 
quebradas podemos encontrar rocas sometidas a procesos aluviales que involucran altas energías y lapsos de menor energía según el régimen hidrológico. Al realizar un muestreo en superficie podemos seleccionar las rocas en función de su contexto depositacional y así interceptar mayor variabilidad de casos a fin de identificar los potenciales agentes tafonómicos.

La muestra de rocas de la quebrada Mal Paso se obtuvo en un tramo de $5 \mathrm{~km}$ al interior, en lo que corresponde a una antigua terraza de abrasión marina, a unos 100 msnm (Varela, 1981; Ortega, Vargas, Rutllant, Jackson y Méndez, 2012). Se realizó un muestreo en un tramo de aproximadamente $2,2 \mathrm{~km}$ de la quebrada, recorriendo las terrazas y el lecho del cauce inactivo, recolectando rocas que mostraran la presencia de cicatrices en los bordes o bien rasgos que imitaran las propiedades de fractura concoidal (Figura 2). La muestra reunida consiste en 94 piezas, de las cuales el 29,79\% ( $n=28)$ fue extraído desde el cauce seco de la quebrada y el 70,21\% ( $\mathrm{n}=66)$ desde las terrazas aluviales aledañas. Las piezas recolecta- das consistieron en rocas volcánicas (principalmente tobas de lapilli), algunas lutitas y otras rocas silicificadas menos representadas presentes en la litología de los conjuntos de QSJ (Méndez, 2015; Méndez y Jackson, 2015). Para efectos de este trabajo, dividimos el conjunto distinguiendo las rocas de grano fino de las rocas de grano medio a grueso, las que corresponden al $32,98 \%(n=31)$ y $67,02 \%(n=63)$ de la muestra, respectivamente. El rango de masa por pieza va desde un mínimo de $13,7 \mathrm{~g}$ hasta un máximo de 1922,4 g.

Los materiales de QSJ consisten en un conjunto lítico recuperado en la unidad estratigráfica 37 , correspondiente al estrato de turba que contiene el contexto arqueológico finipleistoceno. Este consiste en 987 piezas, de las cuales 969 corresponden a desechos de talla y 378 en estado completo (Méndez, 2015). La muestra analizada consistió en 28 piezas, las cuales fueron seleccionadas en función de la presencia de cicatrices en uno o más bordes o bien por la presencia de rasgos típicos de lascas. La muestra incluyó fragmentos de instrumentos formatizados,

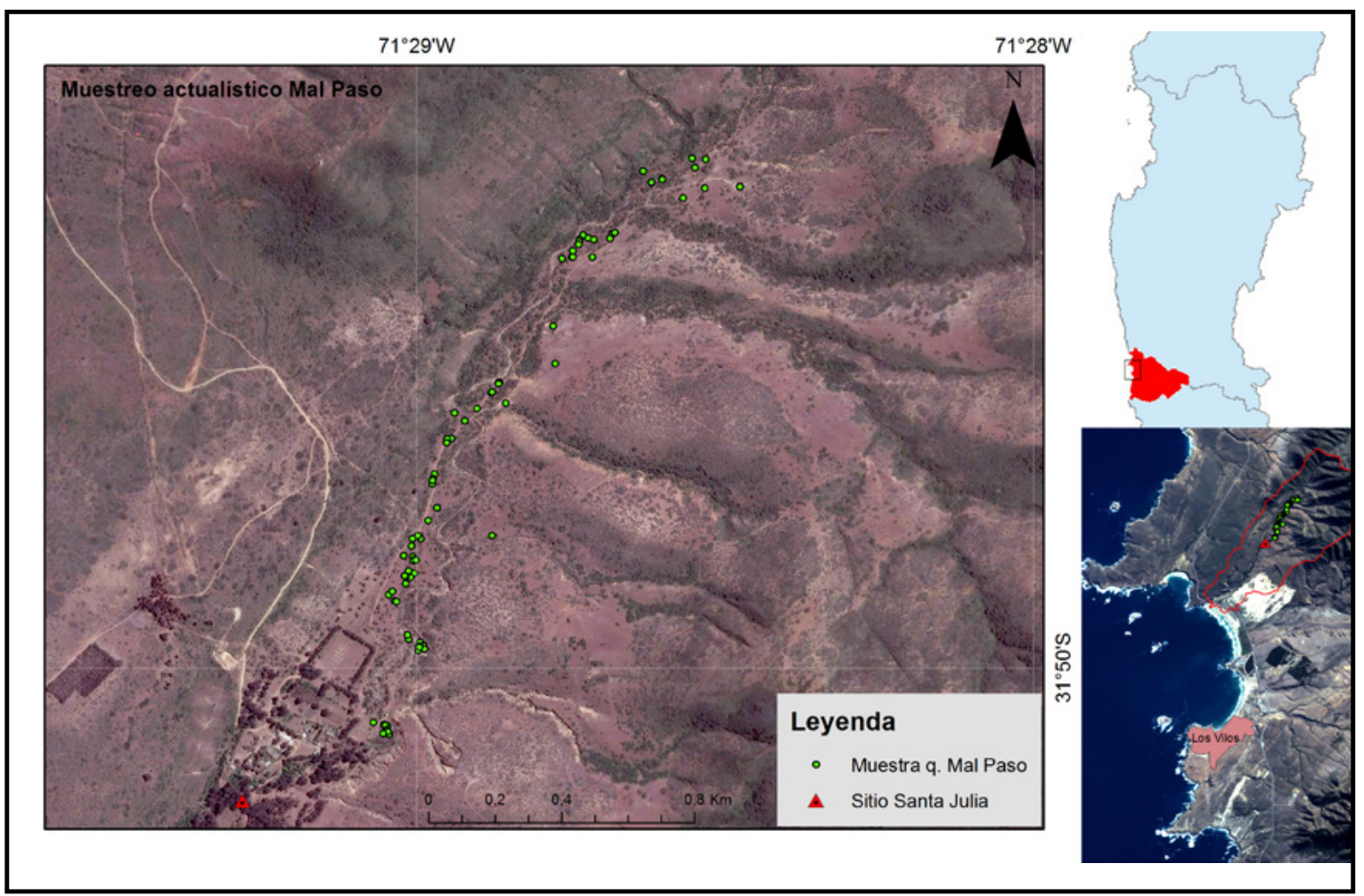

Figura 2. Mapa del muestreo actualístico en quebrada Mal Paso. 
lascas, nódulos y algunos subproductos de talla. La mayoría del conjunto se trata de lascas $(79,62 \%$, $\mathrm{n}=21$ ). Basándonos en los "grupos tecnológicos" de materias primas definidos por Méndez (2015), se identificó cristal de cuarzo, toba-riolita y lutita. El espectro de masa analizado abarca desde un subproducto de talla de cristal de cuarzo de $0,1 \mathrm{~g}$ hasta un núcleo de lutita de $1951 \mathrm{~g}$.

Del conjunto lítico de QQ, se excluyeron todos los artefactos procedentes de las unidades estratigráficas superiores fechadas hacia 2800-2300 cal AP que corresponden a puntas de proyectil triangulares e instrumentos sobre matrices de guijarros, incluyendo ejemplares de piedra pulida (Núnez et al., 1994; Méndez, 2004). La muestra estudiada corresponde a un total de 96 piezas líticas. Se tomó la decisión de considerar piezas de toda la secuencia estratigráfica con la finalidad de detectar procesos tafonómicos que pudieron haber afectado diferencialmente a las rocas de los niveles pleistocenos. La mayor parte del conjunto consiste en nódulos $(64,48 \%)$ y clastos con algún atributo que permite discutir su potencial antropogénico $(34,79 \%)$. La muestra abarca piezas que van desde una pequeña lasca de grano fino de 3 $\mathrm{g}$ hasta un nódulo de $2027 \mathrm{~g}$.

Las materias primas fueron clasificadas en dos grandes grupos: rocas de grano fino y rocas de grano medio. Las primeras corresponden al 15,01\% de la muestra e incluyen, entre otras, rocas silíceas oscuras, verdosas y púrpuras, tobas silicificadas y un tipo de rocas afaníticas porfídicas. El segundo grupo, que abarca el $84,99 \%$ de la muestra y corresponde a la microdiorita/diabasa de grano medio-fino reconocida por Núñez y colaboradores (1994), la cual se aprecia en distintas tonalidades de grises a beige.

\section{Método}

Dado que todos los conjuntos líticos son alterados por procesos tafonómicos (Borrazzo, 2006), nuestro análisis busca en primer lugar identificar estos procesos suprimiendo momentáneamente su dimensión arqueológica, considerándolos solo como partículas sedimentarias (Schiffer, 1983). Posteriormente, evaluamos la ocurrencia de rasgos generados típicamente en un proceso tecnológico
(Inizian, Reduron-Ballinger, Roche y Tixier, 1999; Andrefsky, 2005) para luego discriminar cuáles son atributos antropogénicos a partir del contraste entre conjuntos líticos de orígenes conocidos (muestras de control) y el conjunto en el foco de nuestro análisis: Quebrada de Quereo.

El análisis de las piezas consideró rasgos genéricos como forma base (distinción entre lasca o nódulo), materia prima, peso, largo, ancho y espesor máximos. Se definió una serie de atributos tafonómicos y tecnológicos sobre los cuales se centró el análisis.

\section{Rasgos tafonómicos}

Identificadas macroscópicamente, a través de una escala ordinal con estas variables se busca registrar los efectos de la meteorización física y química sobre las rocas.

Abrasión: meteorización física generada por el roce de partículas de menor tamaño transportadas por agua o viento (Peacock, 1991; Borrazzo, 2011). Una roca con biseles redondeados, superficie y aristas suavizadas tiene mayor abrasión frente a una roca que presenta biseles vivos, aristas aguzadas y texturas más irregulares. Se definió una escala ordinal, como otros autores han realizado (p.e., Borrazzo, 2006; Ugalde et al., 2015), la cual parte en 0 (biseles vivos, aristas agudas), sigue con 1 (presencia de trituramiento), continua con 2 (redondeado leve) y termina con 3 (redondeado avanzado).

Diferencias de coberturas de roca: la exposición a través del tiempo a los agentes causantes de la meteorización química provoca en las rocas el desarrollo de coberturas de roca o rock coatings (Dorn, 1998). Estas tienden a ser homogéneas en todas las caras expuestas a los agentes ambientales, por lo que al producirse una fractura la superficie generada mostrará un menor desarrollo de cobertura al tener un tiempo de exposición menor que el resto de la pieza (Oakley, 1968; Patterson, 1983).

Similar a otros autores (p.e., Hiscock, 1985; Balirán, 2014), se definió una escala ordinal. En nuestro caso, la variable se registró contabilizando las diferencias de color y textura de la superficie de cada 
roca, de manera que 0 es la ausencia de diferencias de coberturas, 1 es la presencia de una diferencia de coberturas, y así sucesivamente.

\section{Rasgos tecnológicos}

Se registraron rasgos de lascas como el tipo de talón, presencia de bulbo de percusión, porcentajes de corteza, aristas (Peacock, 1991; Gillespie, Tupakka y Cluney, 2004; Lubinski, Terry y McCutcheon, 2014). Se denominó "matrices tipo lasca" a todas aquellas piezas donde fuera posible hacer la distinción anverso-reverso, o bien se pudiera identificar una zona proximal.

El borde activo (Bate, 1971) de los posibles instrumentos fue el foco principal del análisis, en tanto que en el conjunto lítico de QQ el patrón "filo uso ocasional" de los instrumentos se basa en la apreciación de un borde astillado frente a un borde opuesto no trabajado (Núńez et al., 1994).

Para seleccionar el potencial borde activo, se contabilizó el número de cicatrices (tamaño mínimo de 2 mm, Andrefsky, 2013; Borrazzo, 2016) escogiendo el borde con mayor cantidad de negativos. En este borde se midió el ángulo y forma de la zona astillada, la extensión facial de los astillamientos (unilateral, bilateral o marginal), así como la continuidad (cicatrices contiguas una junto a otra en el borde), superposición (cicatrices superpuestas sobre una serie de astillamientos más grandes) y alineamiento (los astillamientos están ordenados en la misma dirección) (Patterson, 1983; Gillespie et al., 2004; Schulz, 2010). Se midió la proporción de la zona astillada del borde, el espesor del borde astillado, y el ángulo natural del borde (medido en la zona sin astillar del borde activo), a través de los cuales buscamos registrar la "línea de menor resistencia" (sensu Warren, 1905), vale decir, aquella zona del borde más delgada y frágil y, por lo tanto, más propicia a las fracturas naturales (Balirán, 2014; McPherron et al., 2014; Weitzel, Borrazzo, Ceraso y Balirán, 2014; De la Peña y Witelson, 2018).

Los atributos tafonómicos "abrasión" y "coberturas de roca” fueron también registrados a nivel del borde activo, considerando solo las alteraciones en dicho borde. La combinación de estos atributos permitió construir una categoría de "nivel de meteorización", la cual fue utilizada para la clasificación de las piezas.

Nuestra evaluación de la cualidad antropogénica de las piezas se basó en una clasificación jerárquica, con la cual buscamos sopesar el efecto en la percepción de la configuración de las cicatrices en los bordes activos de las piezas, según lo que hemos denominado atributos de astillamiento lógico. Partiendo del principio básico de que el borde tenga un ángulo menor a 90 grados, dividimos la muestra en cinco grupos, en los cuales el grupo A es el que representa, en combinación con otros rasgos, las piezas más cercanas a las expectativas de un artefacto propiamente antropogénico (Tabla 1).

Tabla 1. Grupos según atributos de astillamiento lógico.

\begin{tabular}{|c|c|c|c|c|}
\hline & $\begin{array}{c}\text { Ángulo } \\
<=90^{\circ}\end{array}$ & $\begin{array}{c}\text { Continuidad } \\
\text { cicatrices }\end{array}$ & $\begin{array}{c}\text { Superposición } \\
\text { cicatrices }\end{array}$ & $\begin{array}{c}\text { Alineamiento } \\
\text { cicatrices }\end{array}$ \\
\hline Grupo A & sí sí & sí & no & sí, sin superposición alineamiento \\
\hline Grupo B & sí & sí & no & no \\
\hline Grupo C & sí & sí & no & no \\
\hline Grupo D & si & no & no & no \\
\hline
\end{tabular}




\section{Resultados}

\section{Características tafonómicas,} pseudoartefactos y artefactos en la muestra de quebrada Mal Paso

Los rasgos tafonómicos registrados en la muestra de quebrada Mal Paso estuvieron condicionados por el lugar desde donde fueron obtenidas las piezas en el muestreo: el cauce de la quebrada y las terrazas aluviales aledañas. Comparativamente, se observan niveles altos de meteorización en el cauce de la quebrada, en tanto se registra una mayor proporción de piezas con niveles altos de abrasión y varias coberturas de roca, además de una menor proporción de piezas con niveles bajos en estos atributos (Figura 3a y b).

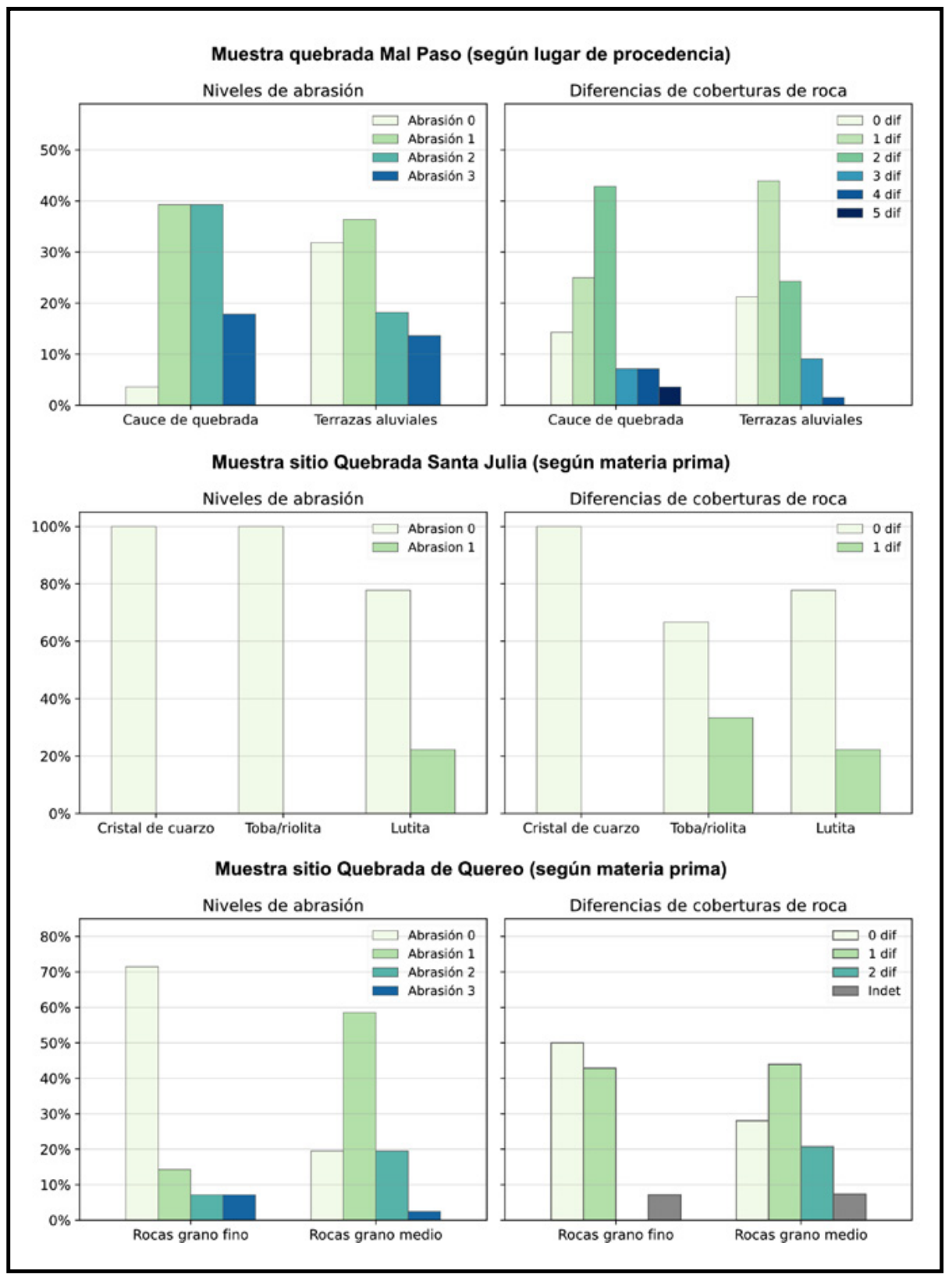

Figura 3. Gráficos de niveles de meteorización en todas las muestras analizadas. 
Los rasgos tafonómicos a nivel de bordes son expresivos de su contexto depositacional, en tanto que en el cauce de la quebrada se observan mayores niveles de abrasión en el borde que en las terrazas aluviales (92,86\% frente a 71,43\% con presencia de abrasión, respectivamente). En cuanto a las diferencias de coberturas de roca, se observa una proporción mayor de piezas con una o más diferencias en el cauce de la quebrada que en las terrazas aluviales $(82,14 \%$ y $73,02 \%$ respectivamente) (Figura $4 \mathrm{a} \mathrm{y} \mathrm{b}$ ).

El estado de meteorización de los bordes permite ensayar una matriz de clasificación con la cual podemos esquematizar la apariencia más o menos antropogénica de la muestra a partir del supuesto borde activo de cada pieza (Tabla 2). Los "grupos

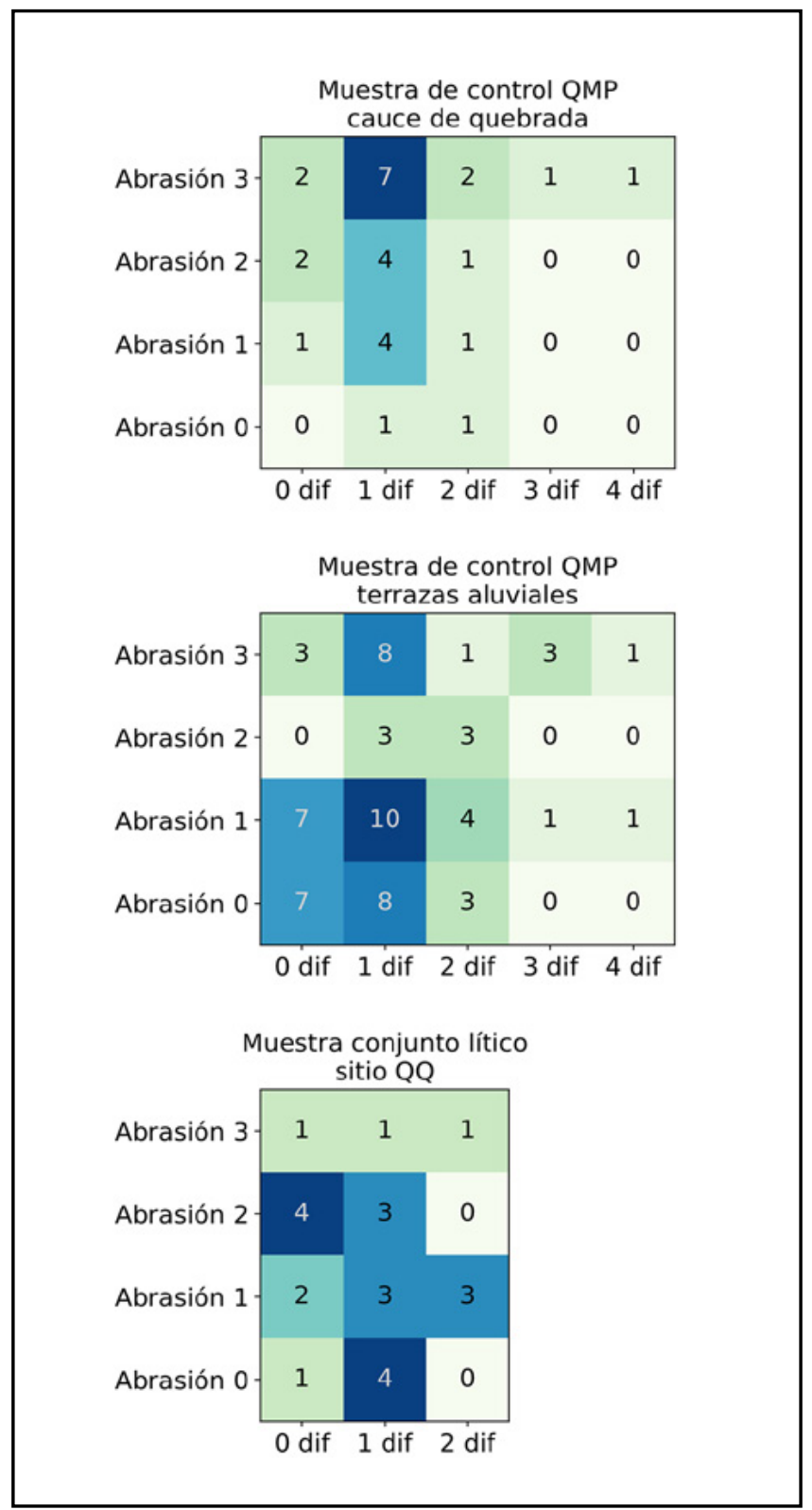

Figura 4. Gráficos (mapas de calor) de frecuencias absolutas de niveles de meteorización del borde en las muestras de control de quebrada Mal Paso (a y b) y del sitio Quebrada Quereo (c). 
de astillamiento lógico" A, B y C, una extensión facial unilateral y los bordes con mayor cantidad de cicatrices de cada grupo representan las piezas con mayor aspecto antropogénico. Por otro lado, los es- tados de abrasión del borde abrasión 2 (redondeados) y con mayor cantidad de coberturas de roca en el borde apuntan a un origen natural de la zona activa (Figura 5).

Tabla 2. Clasificación de la muestra de quebrada Mal Paso según atributos del borde activo.

\begin{tabular}{|c|c|c|c|c|c|c|c|c|c|c|c|c|c|c|c|c|c|c|c|}
\hline & & & \multicolumn{16}{|c|}{ Abrasión del borde } & \multirow[b]{3}{*}{ Total } \\
\hline & & & \multicolumn{3}{|c|}{ Abrasión 0} & \multicolumn{5}{|c|}{ Abrasión 1} & \multicolumn{3}{|c|}{ Abrasión 2} & \multicolumn{5}{|c|}{ Abrasión 3} & \\
\hline \multicolumn{3}{|c|}{ Dif. de coberturas de roca } & $\mathbf{0}$ & 1 & 2 & $\mathbf{0}$ & 1 & 2 & 3 & 4 & $\mathbf{0}$ & 1 & 2 & $\mathbf{0}$ & 1 & 2 & 3 & 4 & \\
\hline Grupo & $\begin{array}{c}\text { Extensión } \\
\text { facial }\end{array}$ & $\begin{array}{c}\mathrm{N}^{\circ} \mathrm{de} \\
\text { cicatrices }\end{array}$ & & & & & & & & & & & & & & & & & \\
\hline \multirow{6}{*}{$\begin{array}{c}\mathbf{A} \\
\mathbf{N}=\mathbf{1 7}\end{array}$} & Unilateral & $>10$ & & 1 & & & 1 & & 1 & & & & & & & & & & 3 \\
\hline & & 6 a 10 & & 1 & & 1 & 2 & & & 1 & & 1 & & & & & & & 6 \\
\hline & & 1 a 5 & & & & & & 1 & & & & 1 & & & & & & & 2 \\
\hline & Bilateral & $>10$ & & & & 1 & & & & & & & & & & & & & 1 \\
\hline & & 6 a 10 & & & & 1 & 1 & & & & & & & & & & 1 & 1 & 4 \\
\hline & & 1 a 5 & & & & & & & & & & & & & & 1 & & & 1 \\
\hline \multirow{5}{*}{$\begin{array}{c}\mathrm{B} \\
\mathrm{N}=29\end{array}$} & Unilateral & 6 a 10 & & & 1 & & 1 & & & & & & & & & & & & 2 \\
\hline & & 1 a 5 & 2 & & & 1 & 1 & 1 & & & & & 1 & 1 & 1 & & & & 8 \\
\hline & Bilateral & $>10$ & & & & & & & & & & & & & & & 1 & & 1 \\
\hline & & 6 a 10 & 1 & & 1 & & 1 & & & & & & & & 4 & 1 & & 1 & 9 \\
\hline & & 1 a 5 & & 2 & 1 & & 2 & 1 & & & 1 & 1 & & & 1 & & & & 9 \\
\hline \multirow{3}{*}{$\begin{array}{c}\mathrm{C} \\
\mathrm{N}=17\end{array}$} & Unilateral & 1 a 5 & 1 & & & & & & & & & & & & & & & & 1 \\
\hline & Bilateral & 6 a 10 & & & & & 1 & 1 & & & & & 1 & & 3 & & 1 & & 7 \\
\hline & & 1 a 5 & & 1 & & 2 & & & & & & 1 & 1 & 1 & 2 & 1 & & & 9 \\
\hline \multirow{4}{*}{$\begin{array}{c}\mathrm{D} \\
\mathrm{N}=23\end{array}$} & Unilateral & 1 a 5 & & 1 & & & 1 & & & & & & & & & & & & 2 \\
\hline & Bilateral & 6 a 10 & & & & & & & & & 1 & & & & & & & & 1 \\
\hline & & 1 a 5 & & 1 & & 1 & 2 & & & & & 2 & 1 & 1 & 1 & & 1 & & 10 \\
\hline & Marginal & 1 a 5 & 2 & 1 & & 1 & & & & & & & & 1 & 1 & & & & 6 \\
\hline \multirow{2}{*}{$\begin{array}{c}E \\
N=9\end{array}$} & Unilateral & 1 a 5 & 1 & 1 & & & & 1 & & & & 1 & & & 1 & & & & 5 \\
\hline & Bilateral & 6 a 10 & & & 1 & & 1 & & & & & & & 1 & 1 & & & & 4 \\
\hline & & Total & 7 & 9 & 4 & 8 & 14 & 5 & 1 & 1 & 2 & 7 & 4 & 5 & 15 & 3 & 4 & 2 & 91 \\
\hline
\end{tabular}




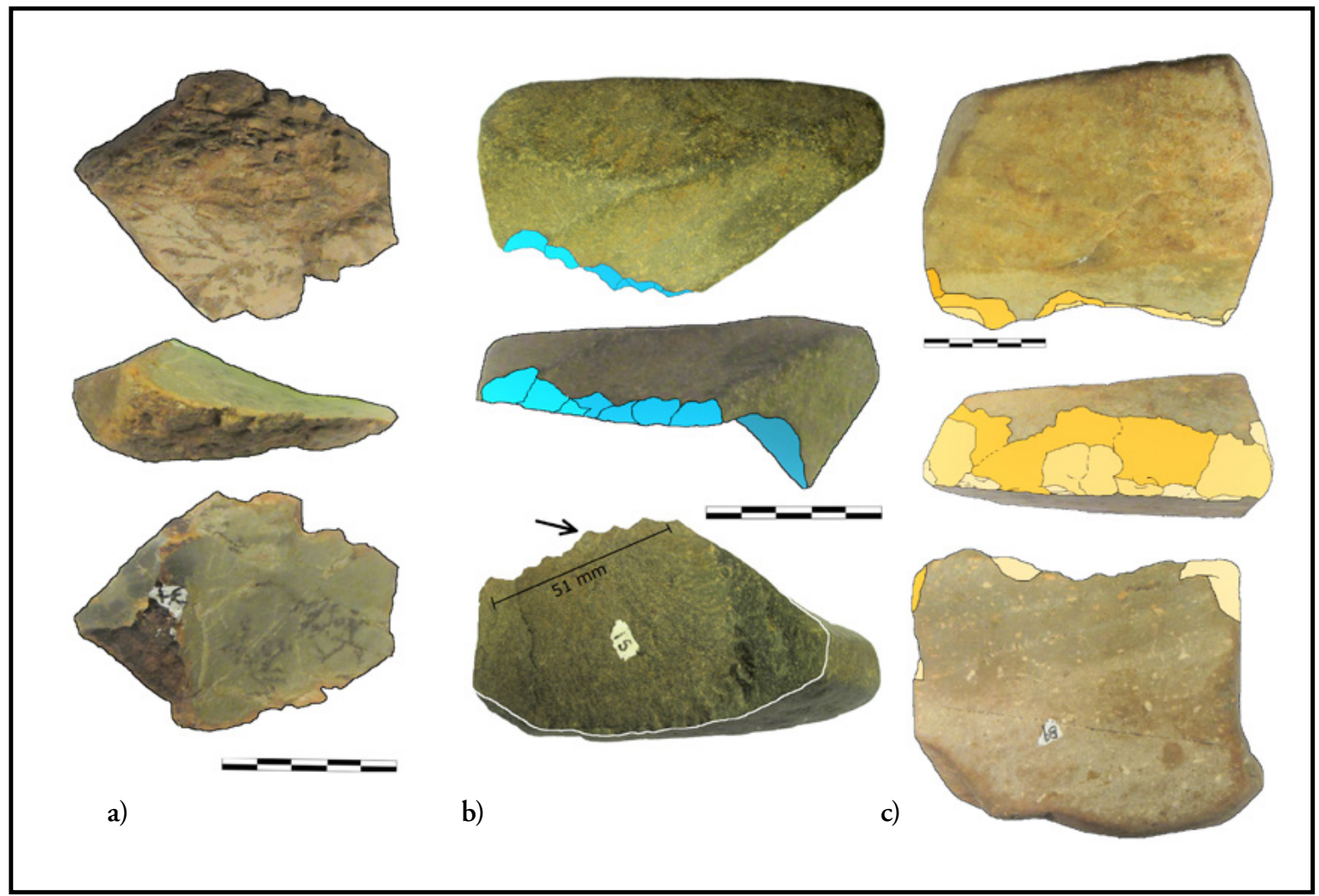

Figura 5. Pseudoartefactos muestra quebrada Mal Paso. Escala gráfica: $5 \mathrm{~cm}$.

En cuanto a la muestra de rocas que asemejan lascas ("matrices tipo lasca"), estas presentan escasos atributos tecnológicos. Buena parte de los "talones" son naturales y planos, aunque en algunos casos la identificación de la zona proximal fue dudosa. En todas las piezas donde identificamos un bulbo de percusión, este es difuso.

Otras observaciones de la muestra de quebrada Mal Paso resultaron significativas para nuestro trabajo. Un $89,82 \%$ de la muestra tiene los bordes con ángulos menores a 90 grados, lo cual expresa que este atributo es irrelevante para detectar un comportamiento tecnológico (Patterson, 1983), sobre todo cuando la forma del borde no se configura por los astillamientos. Los rasgos "alineamiento" y "extensión facial unilateral" parecen ser menos frecuentes en conjuntos naturales, rondando ambos el 30\% de la muestra. La cantidad de cicatrices en un borde resultó ser determinante para la apreciación de estos rasgos, en tanto que, a mayor cantidad de cicatrices, estos adquieren una apariencia más cercana a lo antropogénico.

\section{Tafonomía lítica del sitio Quebrada Santa Julia}

En QSJ las materias primas marcaron las principales tendencias, siendo las lutitas, aunque en un nivel bajo, las que se mostraron más afectadas por la abrasión; mientras que las piezas de cristal de cuarzo no presentan meteorización (ver Figura 3c y d).

Destaca un tipo de cobertura de roca oxidada que se expande cubriendo algunas cicatrices. En algunos casos una costra anaranjada recorre la pieza siguiendo un patrón radicular que no se ve interrumpido por las zonas astilladas, lo cual es un indicio de un origen posdepositacional (Figura 6). En algunos especímenes de toba/riolita este patrón mostró un notable predominio en una sola cara de las piezas, mientras que en las lutitas se observó una distribución más homogénea. En las piezas de cristal de cuarzo no se observaron estas improntas, aunque unas muy tenues y pequeñas marcas anaranjadas podrían ser tomadas como un desarrollo incipiente de este rasgo. 


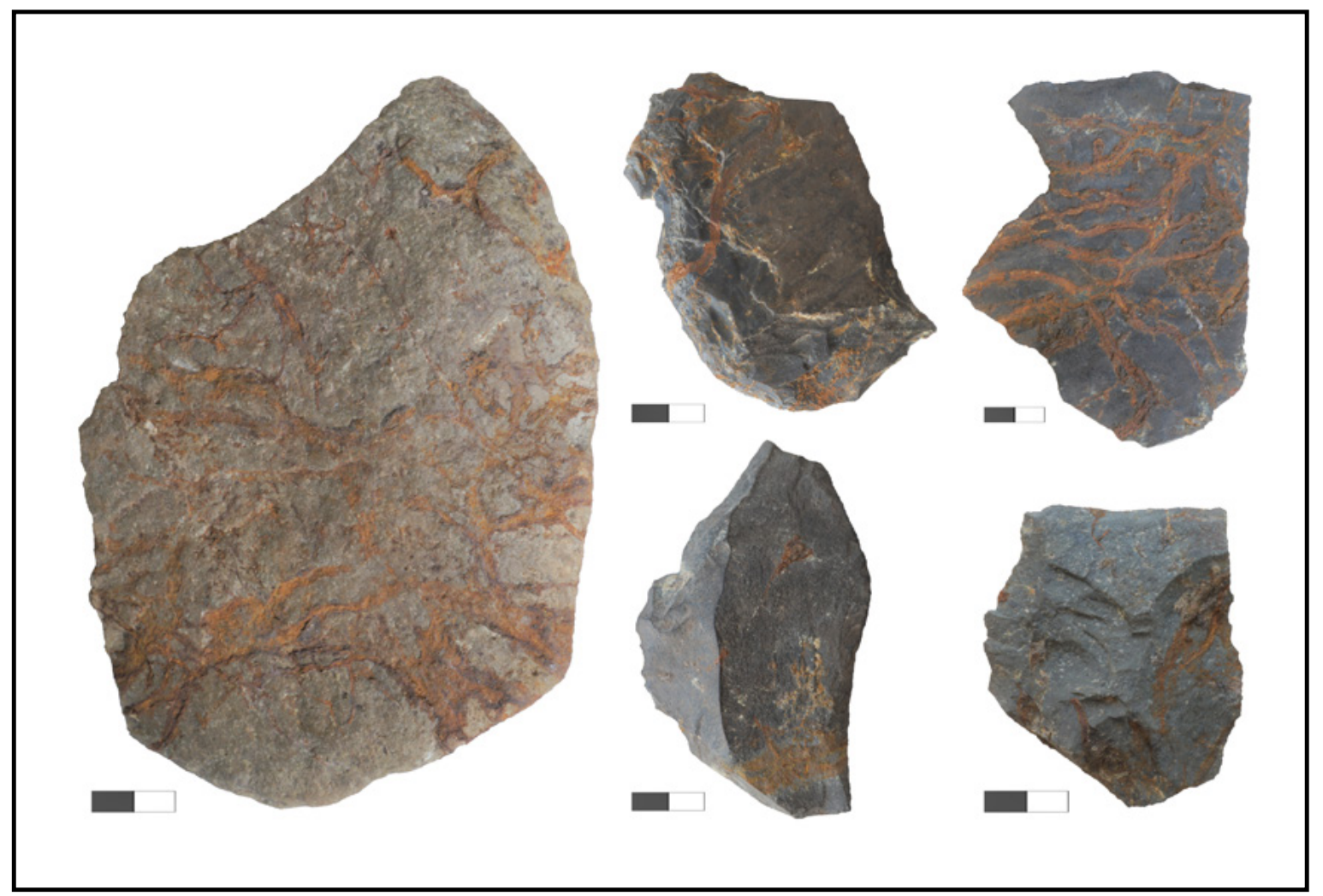

Figura 6. Manchas de oxidación e improntas de raíces oxidadas en artefactos de QSJ. Escala gráfica: $2 \mathrm{~cm}$.

Tabla 3. Clasificación de la muestra de QSJ según atributos del borde activo.

\begin{tabular}{|c|c|c|c|c|c|c|}
\hline & & & \multicolumn{4}{|c|}{ Abrasión del borde } \\
\hline & & & & & Ab. 1 & Total \\
\hline \multicolumn{3}{|c|}{ Diferencias de coberturas de roca } & 0 & 1 & 0 & \\
\hline Grupo & Extensión facial & $\mathrm{N}^{\circ}$ cicatrices & & & & \\
\hline \multirow{3}{*}{$\mathbf{A}$} & Bifacial & $>10$ & 2 & & & 2 \\
\hline & Unilateral & $>10$ & 3 & 2 & & 5 \\
\hline & Marginal & $>10$ & & & 1 & 1 \\
\hline B & Unilateral & 6 a 10 & 1 & & & 1 \\
\hline $\mathrm{C}$ & Bilateral & 6 a 10 & 1 & & & 1 \\
\hline \multirow{2}{*}{ D } & Unilateral & 6 a 10 & 1 & & & 1 \\
\hline & Marginal & 1 a 5 & & 1 & & 1 \\
\hline \multirow{2}{*}{$\mathbf{E}$} & Indet & indet & & & 1 & 1 \\
\hline & & Total & 8 & 3 & 2 & 13 \\
\hline
\end{tabular}


En un $80,95 \%$ de la muestra de QSJ se observa bulbo de percusión en la cara ventral, a la vez que se aprecian atributos como variabilidad de talones (naturales, planos, facetados, pseudofacetados y puntiformes) y evidencia de preparación del borde adyacente al talón (Méndez, 2010). Además, si aplicamos el esquema de clasificación de los atributos del borde activo (Tabla 3) observamos astillamiento unilateral y altas cantidades de negativos en el borde.

\section{Evaluación tafonómica y tecnológica del conjunto lítico del sitio Quebrada de Quereo}

En el conjunto de QQ (ver Figura $3 e$ y f), un $72,92 \%$ de la muestra tiene algún nivel de abrasión, mientras que un $61,46 \%$ presenta alguna diferencia de cobertura de roca. Si se considera la materia prima, este atributo se observa en un $80,49 \%$ de las piezas de grano medio (microdioritas/diabasas) y solo en el 28,57\% de las piezas de grano fino. En la mayoría de las rocas de grano medio se observa el desarrollo de una cobertura de roca de distintas tonalidades gris a beige en toda la superficie, la cual dificulta la diferenciación de las zonas libres de corteza. En la mayoría de los casos esta cobertura tiene además improntas oxidadas de similares características, aunque con menor intensidad, a las de QSJ (Figura 7a y b).

Del total de la muestra de QQ, 30 piezas fueron identificadas como matrices con atributos de lascas. Estas presentan atributos morfológicos relacionados con el tipo de fractura "laminar" de la microdiorita/ diabasa, lo que conlleva formas relativamente delgadas (espesor promedio de 12,74 $\mathrm{mm}$ ) con caras planas limitadas por bordes rectos; lo que, en definitiva, se asemeja a lascas erráticas con un reverso plano y presencia de talón. De estas piezas, sólo cuatro son de grano fino, y coinciden con las que poseen más atributos tecnológicos.

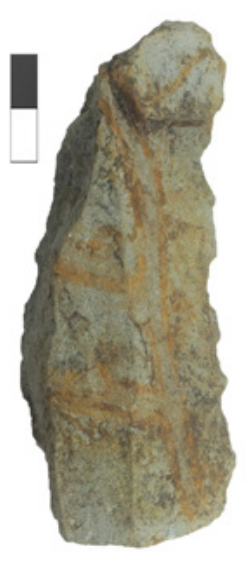

a)
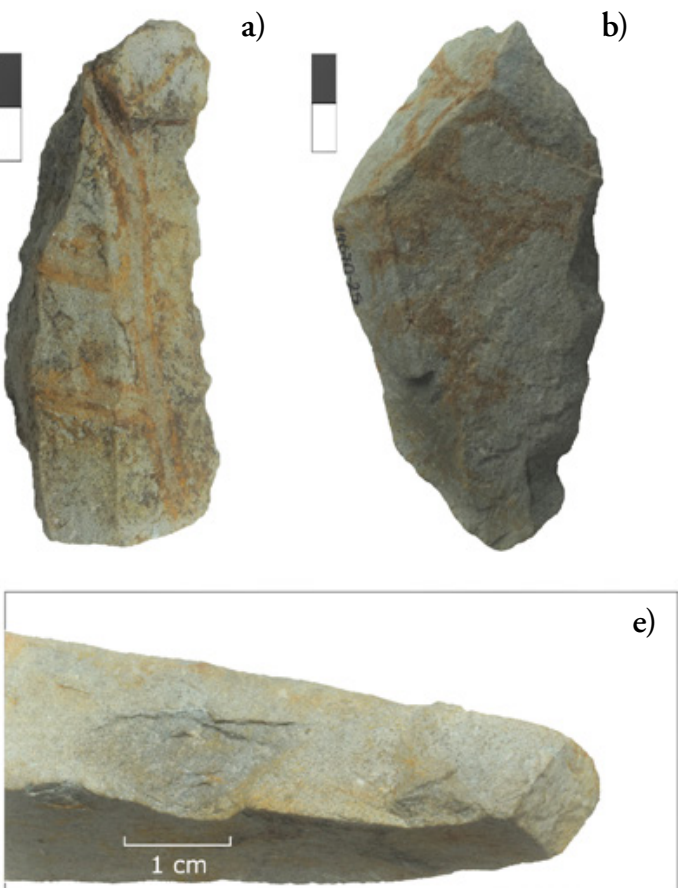

b)


Figura 7. a y b) ejemplos de improntas de raíces oxidadas en Quebrada de Quereo; c y d) ejemplos de clastos con bordes astillados; e y f) ejemplos de marcas de percusión. Escala gráfica: $2 \mathrm{~cm}$. 
Tabla 4. Matrices tipo lasca con un reverso identificado sitio QQ.

\begin{tabular}{|c|c|c|c|c|c|c|}
\hline $\begin{array}{c}\text { Materia } \\
\text { prima }\end{array}$ & Bulbo & Ondas & Estrías & $\begin{array}{c}\text { Desportilladura } \\
\text { bulbar }\end{array}$ & Tipo talón & Corteza Anverso \\
\hline Fino & 0 & 1 & 0 & 1 & plano & 0 \\
\hline Fino & 1 & 0 & 1 & 0 & mixto & 0 \\
\hline Fino & 1 & 1 & 1 & 0 & con preparación & 0 \\
\hline Fino & 1 & 0 & 0 & 1 & plano & 10 \\
\hline Medio & 0 & 0 & 1 & 0 & plano & 8 \\
\hline Medio & 1 & 0 & 0 & 0 & plano & 0 \\
\hline Medio & 1 & 0 & 0 & 0 & plano & Indet. \\
\hline Medio & 1 & 0 & 0 & 0 & facetado & 5 \\
\hline Medio & 1 & 0 & 0 & 0 & plano & 10 \\
\hline Medio & 1 & 0 & 0 & 0 & Indet. & 0 \\
\hline Medio & 1 & 0 & 0 & 0 & plano & 9 \\
\hline
\end{tabular}

En el $70 \%$ de las piezas la cara identificada como reverso no tiene una zona bulbar, siendo completamente plano en la mayoría de los casos. En aquellas piezas donde se identifica bulbo de percusión, este siempre es difuso (Tabla 4). Otros atributos potenciales como ondas, estrías o desportilladura bulbar no se observan por el tamaño del grano (Figura $8 \mathrm{e}$ y f).

La mayoría de los "talones" identificados son planos, aunque también se observó un talón facetado, un talón preparado (pequeño labio y superficie triturada) y un talón mixto (con piqueteos y una zona con corteza), los que, sin embargo, no proceden de los niveles pleistocenos de QQ (Figura 8a, b y c).

Destaca el caso de una pieza de una roca de grano fino gris que exhibe ondas y desportilladura bulbar, pero en ausencia de un bulbo de percusión. Presenta un talón plano y un par de aristas en el anverso. Esta pieza es el mejor candidato de un probable origen antropogénico en el nivel Quereo II (Figura 8d).
En QQ una buena parte de las piezas líticas tiene bordes astillados. Esto ocurre de manera frecuente en clastos de forma "laminar" y, en menor medida, en clastos más contundentes en los que las cicatrices son pequeñas (ver Figura $7 \mathrm{c}$ y d). En algunos especímenes podemos observar marcas de percusión (bisagras y algunos negativos de bulbo poco invasivos), lo cual se da tanto en los supuestos bordes potencialmente activos como en las zonas pasivas (ver Figura $7 \mathrm{e} \mathrm{y} \mathrm{f).}$

Para el análisis de los bordes astillados tomamos una muestra de 23 piezas, la cual agrupa todas aquellas piezas que presentan la mayor cantidad de cicatrices en un borde (abarcando desde 5 hasta 10 cicatrices).

Los estados de meteorización del borde más frecuentes resultaron ser: abrasión 2 sin diferencias de coberturas de roca y abrasión 0 con una sola diferencia de coberturas, ambos con 17,4\% (ver Figura 4c). 
a)

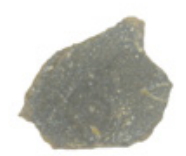

b)

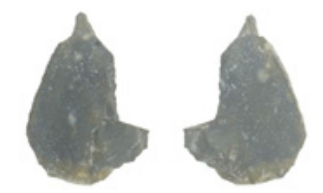

c)
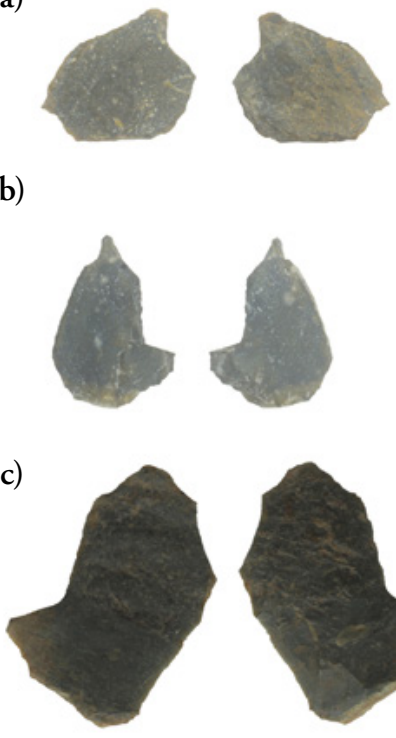

d)

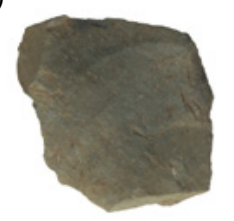

e)

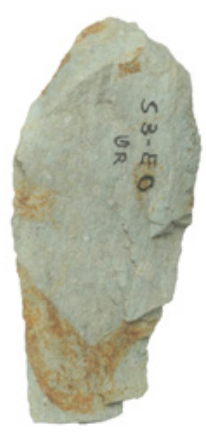

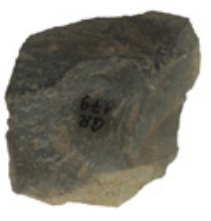

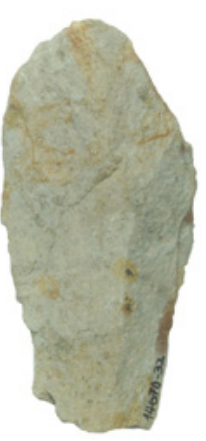

f)
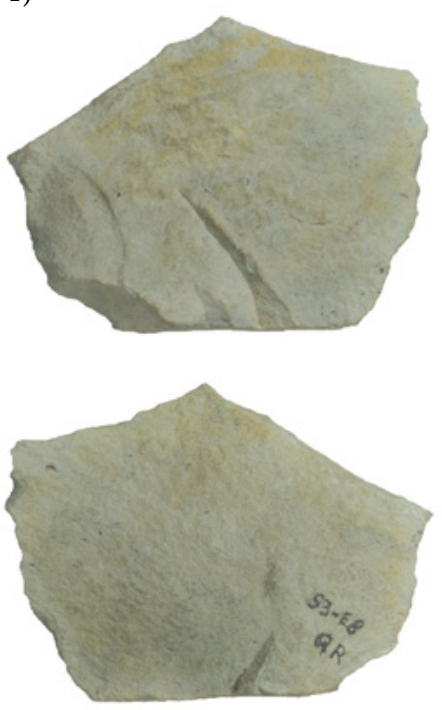

Figura 8. Lascas conjunto lítico Quereo: a, b y c) lascas con talones preparados, niveles tardíos; d) lasca con ondas en el reverso, nivel Quereo II; e y d) matrices tipo lasca de microdiorita/diabasa. Escala gráfica: $2 \mathrm{~cm}$.

En cuanto a las características de los astillamientos, se observa un $43,50 \%$ de bordes con astillamientos con extensión facial unilateral, dato relevante considerando la apariencia de lógica de talla que entrega este atributo. En la gran mayoría de los casos $(86,96 \%)$ se observa continuidad de las cicatrices, lo cual no ocurre con la superposición $(27,74 \%)$. En poco más de la mitad de la muestra se pudieron apreciar cicatrices alineadas $(47,83 \%)$. En cinco ca- sos se observa continuidad y superposición, mientras que en dos casos se presentan estos tres rasgos en el borde (Tabla 5). La alta incidencia de continuidad y la baja cantidad de piezas con cicatrices superpuestas permite hacerse una idea cabal de las características de los bordes astillados del conjunto lítico de QQ. Veremos que esto se relaciona con el bajo espesor de los bordes de las piezas.

Tabla 5. Presencia de continuidad, superposición y alineamiento en las cicatrices del borde en muestra del sitio QQ (N=23).

\begin{tabular}{|l|c|c|}
\hline Características de los astillamientos & N & $\%$ \\
\hline Continuidad de las cicatrices & 20 & $86,96 \%$ \\
\hline Superposición de las cicatrices & 5 & $41,74 \%$ \\
\hline Alineamiento de las cicatrices & 11 & $21,74 \%$ \\
\hline Continuidad y superposición & 5 & $8,70 \%$ \\
\hline Continuidad, superposición y alineamiento & 2 & $2 \%$ \\
\hline
\end{tabular}




\section{Evaluación de las piezas según "grupos de astillamiento lógico"}

En la Tabla 6 se observa el esquema de clasificación aplicado a la muestra del sitio Quebrada de Quereo. A partir de este describiremos las piezas a nuestro juicio más relevantes del conjunto, con el fin de discutir su calidad antropogénica o natural.

\section{Grupo A}

En este grupo tenemos dos especímenes, uno con una extensión facial unilateral y otra bilateral, con nueve y diez cicatrices en el borde, respectivamente. Ambas piezas son de microdiorita/diabasa y presentan un nivel de meteorización en el borde con abrasión 1 (bisel triturado) con dos diferencias de coberturas de roca.

Tabla 6. Clasificación de la muestra del sitio QQ $(\mathrm{N}=23)$ según atributos del borde activo.

\begin{tabular}{|c|c|c|c|c|c|c|c|c|c|c|c|c|c|}
\hline & & & \multicolumn{11}{|c|}{ Estado de abrasión del borde } \\
\hline & & & \multicolumn{2}{|c|}{ Ab. 0} & \multicolumn{3}{|c|}{ Ab. 1} & \multicolumn{2}{|c|}{ Ab. 2} & \multicolumn{3}{|c|}{ Ab. 3} & \multirow[t]{2}{*}{ Total } \\
\hline \multicolumn{3}{|c|}{ Diferencias de oberturas de roca } & $\mathbf{0}$ & 1 & $\mathbf{0}$ & 1 & 2 & $\mathbf{0}$ & 1 & $\mathbf{0}$ & 1 & 2 & \\
\hline Grupo & $\begin{array}{c}\text { Extensión } \\
\text { facial }\end{array}$ & $\mathrm{N}^{\circ}$ cicatrices & & & & & & & & & & & \\
\hline \multirow{2}{*}{ A } & Unilateral & 6 a 10 & 1 & & & & 1 & & & & & & 1 \\
\hline & Bilateral & 6 a 10 & & & & & 1 & & & & & & 1 \\
\hline \multirow{5}{*}{ B } & Unilateral & 6 a 10 & & 2 & & 1 & & & 1 & & 1 & & 5 \\
\hline & & 1 a 5 & & 1 & & & 1 & & & & & & 2 \\
\hline & Bilateral & $>10$ & & & & & & & 1 & & & & 1 \\
\hline & & 6 a 10 & & & & 1 & & & 1 & 1 & & & 3 \\
\hline & & 1 a 5 & & 1 & & & & & & & & & 1 \\
\hline \multirow{3}{*}{$\mathrm{C}$} & Unilateral & 6 a 10 & & & & & & 2 & & & & & 2 \\
\hline & Bilateral & 6 a 10 & & & 2 & & & 1 & & & & & 3 \\
\hline & & 1 a 5 & & & & & & 1 & & & & & 1 \\
\hline \multirow{2}{*}{ D } & Unilateral & 6 a 10 & 1 & & & 1 & & & & & & & 2 \\
\hline & Bilateral & 1 a 5 & & & & & & & & & & 1 & 1 \\
\hline \multicolumn{3}{|c|}{ Total } & 3 & 4 & 2 & 3 & 3 & 4 & 3 & 1 & 1 & 1 & 23 \\
\hline
\end{tabular}


a)
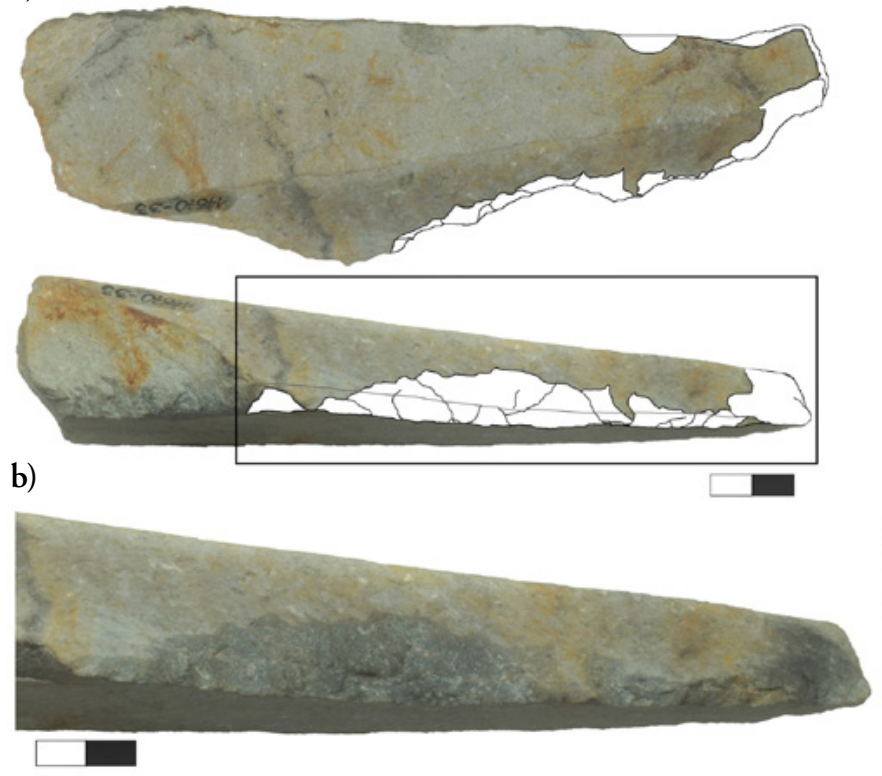

c)

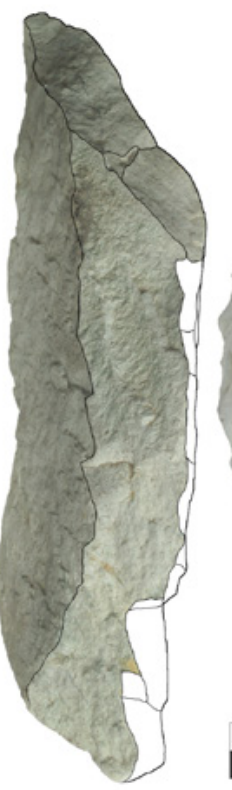



Figura 9. Piezas del grupo A: a) pieza 1; b) pieza 1, detalle del borde astillado; c) pieza 2. Escala gráfica: $2 \mathrm{~cm}$.

Una de estas piezas (Figura 9a y b) corresponde a uno de los "litos laminares", ejemplares del conjunto lítico del nivel Quereo I (Núñez et al., 1994, p. 105). Tiene un peso de $272 \mathrm{~g}$ y destaca por su forma alargada (160 mm y 47,3 mm de largo y ancho máximo, respectivamente). El borde tiene forma irregular, destacando una zona cóncava. En la zona distal el ángulo del borde es agudo, tornándose recto hacia la zona proximal, en donde no presenta astillamientos. Cerca del 75\% del largo del borde activo está astillado (con dos pequeńas interrupciones). Se observan cicatrices pequeñas superpuestas pero discontinuas, las cuales más bien corresponden a pequeños trituramientos limitados por un plano de fractura interno que recorre longitudinalmente la pieza.

La zona astillada destaca por presentarse notoriamente libre de la cobertura de roca gris-beige, mostrando el color original de la roca que corresponde a un gris oscuro. En la cobertura de roca que cubre la zona no astillada se observan marcas de oxidación similares a las demás piezas del conjunto, mostrando un desarrollo más tenue en la zona astillada. Sin embargo, la zona astillada interrumpe claramente estas improntas, dejando una superficie libre. Estas características sugieren un origen reciente.

La segunda pieza de este grupo (Figura 9c) procede del nivel Quereo II y está asociada a un cráneo de Equus sp. Corresponde a un clasto de más de $1 \mathrm{~kg}$ que presenta astillamientos bilaterales de tamańos relativamente uniformes, pero pequeños en relación al espesor de la pieza. Estas cicatrices rectas tienen tamaños diferentes y conforman un borde que en promedio tiene un espesor de 19,1 mm, con un mínimo de 3 a $4 \mathrm{~mm}$, frente a un espesor máximo de la pieza de 41,9 $\mathrm{mm}$, en un borde cubierto en cerca del $80 \%$ por astillamientos. El aspecto alineado de las cicatrices se relaciona con los límites naturales que implica el bajo espesor del borde, en tanto que en la zona medial del borde cada cicatriz contigua tiene un tamaño corto y ancho relativamente uniforme que da una imagen de "orden". Se observan algunas zonas astilladas rectas más grandes hacia los extremos, pero con una cobertura de roca algo más fresca. 
Esta pieza tiene un nivel 2 de abrasión general, y una cobertura de roca gris que cubre buena parte de la zona astillada. Se observan algunas manchas de oxidación tenues. Además, en una de sus caras se puede ver cómo esta litología tiene propensión a un tipo de fractura laminar, lo cual se aprecia en el desprendimiento de una capa de roca, en donde la fractura dejó una cicatriz recta. De hecho, prácticamente todas las cicatrices de esta pieza se superponen sobre una zona adelgazada, con uno o varios desprendimientos grandes que conforman un borde de ángulo agudo. Como veremos, este es un rasgo clave para entender el astillamiento de muchas rocas de Quebrada de Quereo.

\section{Grupo B}

Este grupo consiste en 11 piezas de las cuales 7 presentan astillamientos con una extensión facial unilateral. Se observan bordes con abrasión 0,1 y 2 , con piezas sin cambios de cobertura de roca, así como piezas con una y dos diferencias de cobertu- ra. A continuación, describimos algunas piezas que consideramos útiles para la discusión de nuestro problema.

En la Figura 10 se observa una pieza que tiene la zona astillada en ángulo recto y un borde de forma irregular con una zona cóncava, compuesta por unas cinco cicatrices bilaterales y alineadas, con un estado de abrasión del borde 0 y solo una diferencia de coberturas de roca. En esta pieza la zona astillada revela el color original gris oscuro de esta materia prima, contrastando con la cobertura de roca gris claro cubierta por algunas improntas oxidadas. A partir de las coberturas de roca se pueden discernir al menos dos series de cicatrices producidas en tiempos relativos distintos. También se da una situación similar respecto a la pieza 1 del grupo A (ver Figura 9a y b), en tanto que la zona astillada se muestra libre de improntas de oxidación.

Esta pieza destaca por presentar una concavidad tipo "muesca" conformada por al menos dos cicatrices a)

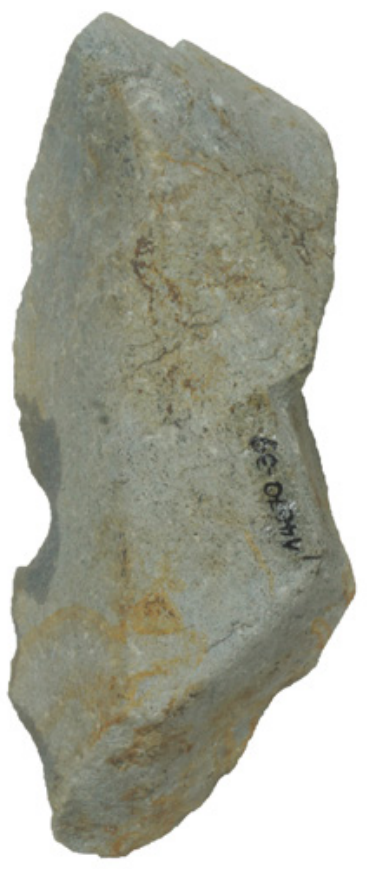

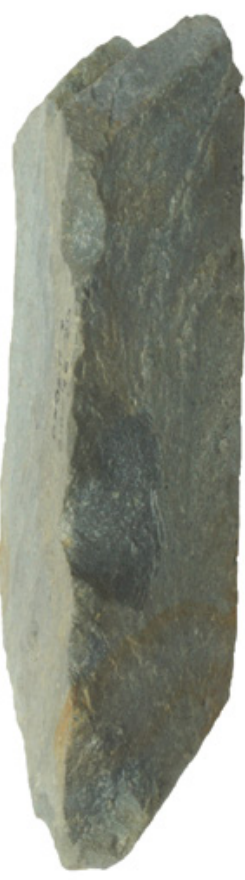

b)
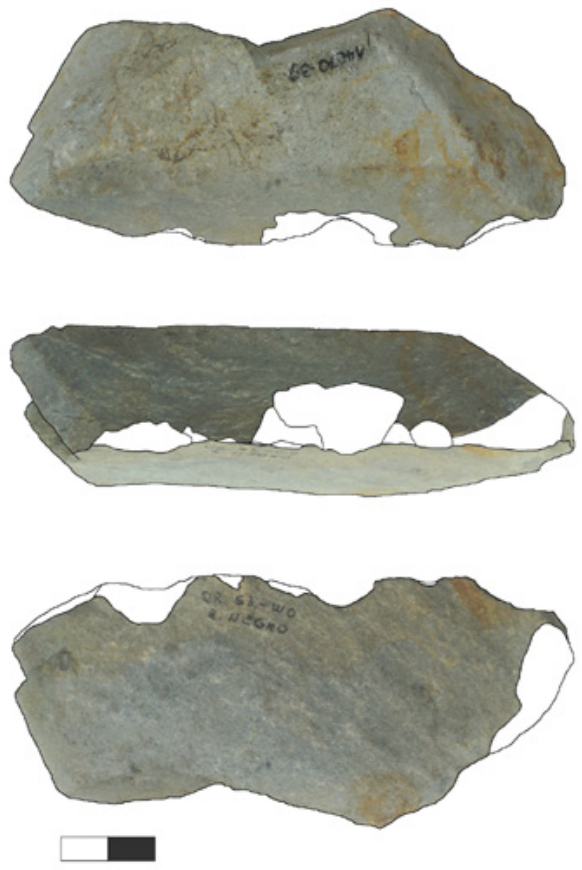

Figura 10. Pieza 1 del grupo B: a) distintas vistas del borde astillado, b) representación de los astillamientos. Escala gráfica: $2 \mathrm{~cm}$. 
que reflejan una acción de percusión, visible a partir de lo que parece ser un punto de impacto y bisagras de relieve suave. La zona no astillada del borde tiene un ángulo agudo, mostrándose propicio para ser tallado; con algunos escasos astillamientos de tamaños disímiles.

La pieza 2 de este grupo (Figura 11 a) tiene un borde de ángulo agudo y una morfología recta, con siete astillamientos unilaterales y alineados, con un borde con abrasión 0 y una sola diferencia de coberturas de roca, pudiéndose distinguir algunas cicatrices libres de cobertura de roca, mostrando el color gris oscuro de esta litología. Similar a la pieza 2 del grupo A (ver Figura 9c), presenta un desprendimiento "laminar", pero afectando buena parte de la superficie de una de sus caras, provocando un ángulo agudo y delgado $(6,8 \mathrm{~mm}$ espesor versus un espesor máximo de la pieza de $12,5 \mathrm{~mm})$. Es desde este plano donde surgen todas las cicatrices que conforman el borde, sirviendo de "plataforma" para los astillamientos.
La pieza 3 (Figura 11b) exhibe a lo menos 11 astillamientos bilaterales continuos y alineados que conforman un borde de ángulo agudo de una forma convexa relativamente bien definida. El borde presenta un estado de abrasión 2, con algunas cicatrices mostrando zonas con menor presencia de la cobertura de roca gris-beige que recubre toda la superficie de la pieza, la cual presenta diversas improntas oxidadas que se pueden observar aún en la zona astillada.

Este caso es un ejemplo de los mencionados "clastos laminares", puesto que su espesor en torno a los 20 $\mathrm{mm}$ no tiene importantes variaciones (espesor máxi$\mathrm{mo}=21,5 \mathrm{~mm}$ ), salvo en el borde, donde disminuye a cerca de $8 \mathrm{~mm}$ en promedio. Se observa una situación similar a piezas anteriormente descritas, en donde una fractura longitudinal recorre el interior de la pieza en la zona del borde astillado.
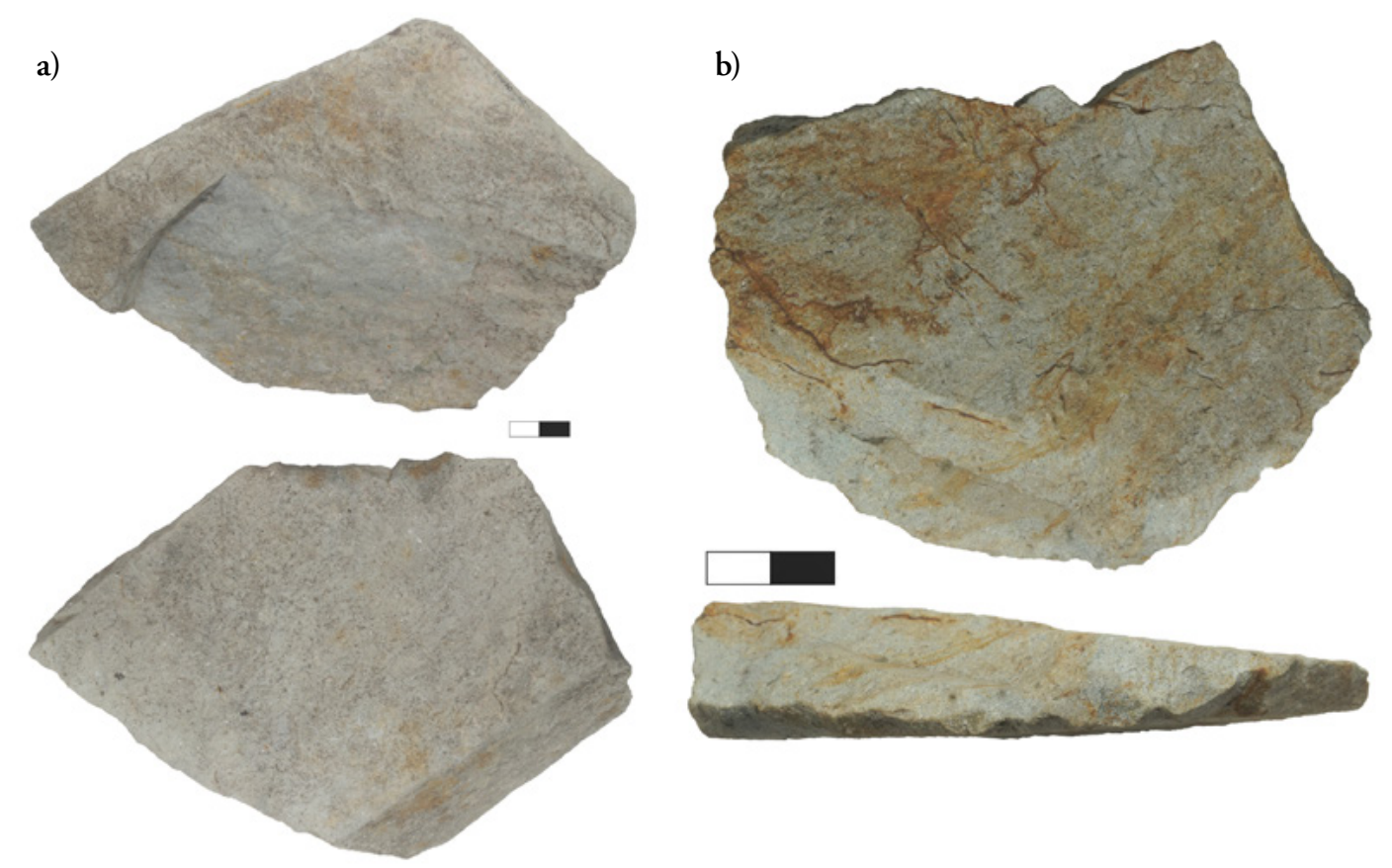

Figura 11. Piezas 2 y 3 del grupo B: a) pieza 2, vistas dorsal y ventral, b) pieza 3, vista frontal y de perfil. Escala gráfica: $2 \mathrm{~cm}$. 


\section{Grupo C}

Este grupo se compone de cinco piezas, dos con astillamiento unilateral y tres con astillamiento bilateral.

Una de las piezas del grupo C (Figura 12a) presenta unos ocho astillamientos unilaterales, conformando una zona astillada de ángulo abrupto. Tiene un borde con abrasión 2, sin observarse diferencias de coberturas de roca. No tiene información asociada respecto a su nivel estratigráfico. Las cicatrices abruptas son de tamańos desiguales, lo que da un aspecto desorganizado que no permite avizorar alineamiento entre ellas. La zona astillada se produce en un borde que, sin considerar las cicatrices (ángulo proyectado) tiene un ángulo promedio de 40 grados, el cual está todo cubierto por una intensa mancha de oxidación en una cara. Tanto en el borde como en el resto de la pieza, es posible observar al menos dos fracturas internas que la recorren, una longitudinal y otra transversal al borde astillado. Esto permite entender que el borde agudo corresponde a un desprendimiento producido por este tipo de fracturas.

\section{Grupo D}

Por último, como ejemplo del grupo $\mathrm{D}$, conformado por aquellas piezas que no registran continuidad en las cicatrices, describimos una pieza (Figura $12 \mathrm{~b}$ ) que consiste en un clasto delgado de forma laminar (espesor máximo $=24,6 \mathrm{~mm}$ ), cuyo borde agudo y de forma recta bien definida (ligeramente convexa) presenta unos seis astillamientos bilaterales. El borde tiene un nivel de abrasión 0, sin diferencias de coberturas de roca, aunque sí hay una diferencia de coberturas entre el borde y el resto de la pieza. En el borde sobre el que se producen las cicatrices se observa una cobertura de roca levemente anaranjada, diferente al resto de la pieza, la cual está separada por una arista que recorre la pieza longitudinalmente.

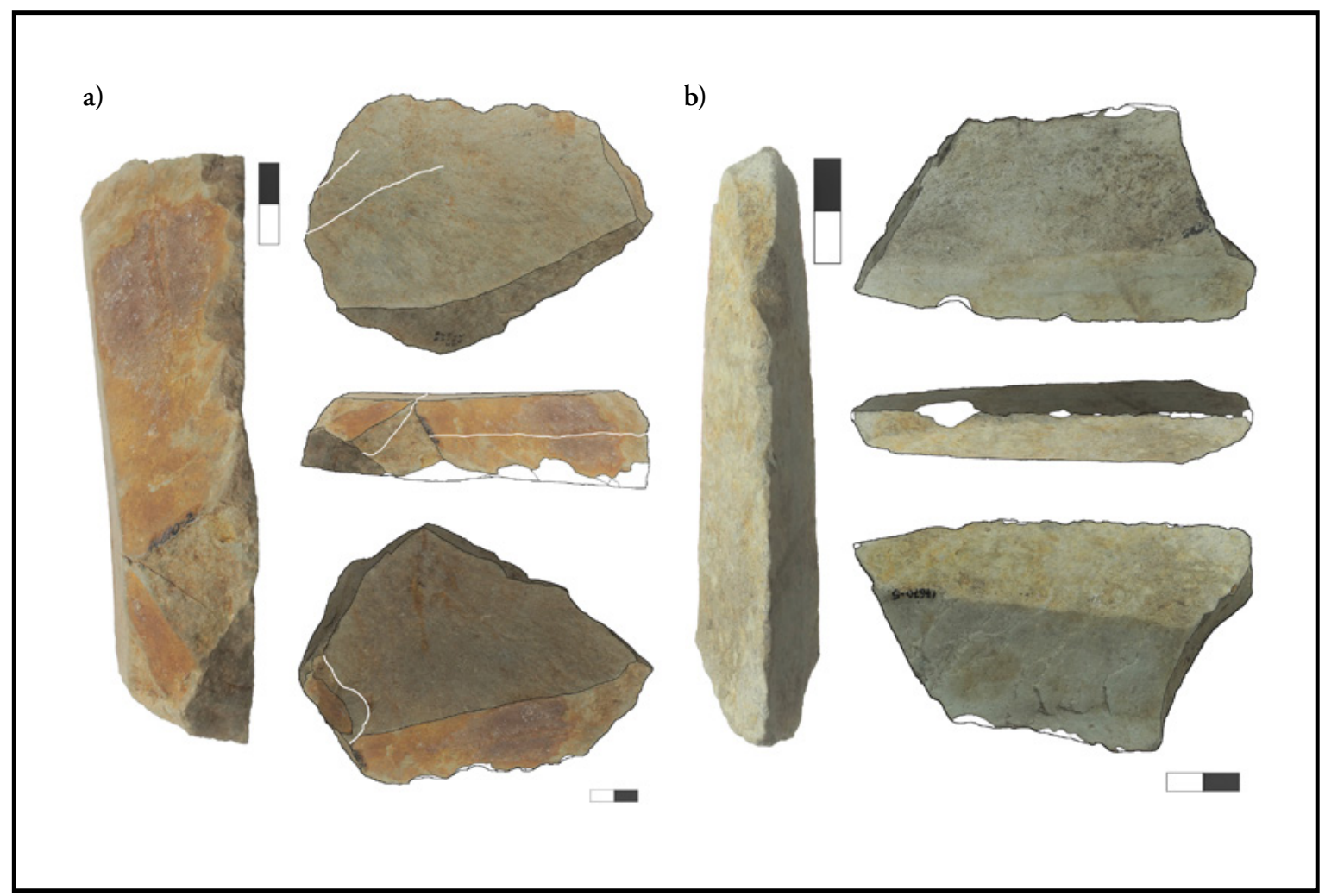

Figura 12. a) pieza del grupo $\mathrm{C}$, detalle borde astillado y representación de los astillamientos (líneas blancas marcan planos de fractura interna); b) pieza 1 del grupo $\mathrm{D}$, detalle del borde astillado y representación de los astillamientos. Escala gráfica: $2 \mathrm{~cm}$. 


\section{Discusión}

\section{Procesos tafonómicos evidenciados en las muestras de control}

El análisis en la muestra de rocas de quebrada Mal Paso permitió inferir dos procesos tafonómicos que pueden generar resultados morfológicos similares a los de un artefacto lítico, principalmente a través del astillamiento natural de los bordes:

- Percusión múltiple por factores de alta energía, en donde el agente se refleja en una mayor cantidad de coberturas de roca y altos niveles de abrasión. Esto ocurre principalmente en la caja de la quebrada, en la cual se produce la energía suficiente para percutir las rocas unas con otras durante los eventos pluviales, lo que a nivel tafonómico se traduce en que cada evento de percusión se superpone al otro, siendo el tiempo relativo entre descargas hídricas el período donde se van desarrollando coberturas de roca sobre las zonas astilladas (Peacock, 1991; Hosfield y Chambers, 2003; Gillespie et al., 2004). En las rocas de las terrazas aluviales estos tiempos relativos serían más extensos, permitiendo un desarrollo de coberturas de roca más homogéneo, reflejando períodos de estabilización del paisaje (Dorn, 1998), lo que permite, por ejemplo, el desarrollo de coberturas litobiónticas.

- Fracturas por factores de menor energía, como termofracturas y pisoteo, en donde una plataforma generada de manera natural permite el astillamiento secuencial de un borde. En este caso, se requiere que la pieza se mantenga en una misma posición durante un tiempo (estabilidad). Las cicatrices pueden ser continuas, pero generalmente son cortas. Dado el régimen de activación de las quebradas en un clima semiárido de régimen torrencial, tanto las rocas del cauce de la quebrada como las de las terrazas aluviales se ven sometidas a agentes no relacionados con el régimen hídrico, como la humedad ambiental, la oscilación de temperaturas, el pisoteo y otros agentes que no producen fracturas por percusión (Hiscock, 1985; Eren et al., 2011).
Asimismo, el análisis en la muestra del sitio QSJ permitió explorar cómo las variables tafonómicas reflejan un depósito aluvial de baja energía, en tanto que las piezas de esta muestra presentan bajos grados de meteorización en todas las variables medidas. Los rasgos tafonómicos de los bordes mostraron ausencia de abrasión y nula incidencia de redondeamiento. Se registró muy baja variación de coberturas de roca tanto en las piezas en general como en sus bordes astillados. Se pudo apreciar que el tipo de materia prima es un factor relevante a la hora de entender los efectos tafonómicos provocados en el contexto deposicional, siendo las lutitas las rocas con mayor grado de alteración. Un aspecto relevante es la presencia de gran cantidad de negativos en piezas pequeñas y livianas (menores a $10 \mathrm{~g}$ ), lo cual ha sido planteado como señal antropogénica en casos ambiguos (Patterson, 1983; Luetdke, 1986).

Un indicio determinante de ambientes depositacionales cargados de humedad son las marcas de oxidación y las improntas de raíces oxidadas. Esto resultó ser clave para nuestro objetivo, en tanto que en el sitio QQ también pudimos observar marcas de óxido similares.

\section{Tafonomía lítica del sitio Quebrada de Quereo}

Rasgos como la abrasión y las coberturas de roca en los bordes de las piezas permiten inferir un proceso tafonómico en el que agentes naturales relacionados con la alta humedad local repercuten en el tipo de meteorización ocurrido sobre las piezas de microdiorita/diabasa. Si bien algunas piezas muestran un grado de redondeamiento que sugiere la acción de algún agente abrasivo a nivel general, el grueso del conjunto no presenta bordes redondeados (nivel de abrasión 3). Este rasgo está influido por la materia prima, en tanto que se observa algún grado de abrasión en el $80,5 \%$ de las piezas de microdiorita/diabasa frente a un $28,6 \%$ de las piezas de grano fino.

Estos aspectos permiten sostener que las piezas de QQ no fueron sometidas a flujos intensos de agua, aun cuando en el depósito sedimentario pudieron ingresar algunos clastos redondeados arrastrados por la quebrada. Esta baja frecuencia podría estar relacionada con la lejanía de la desembocadura respecto 
a sectores de pendientes más abruptas con descargas de mayor energía, como se puede observar, por ejemplo, en el sitio Las Monedas, aguas arriba en la misma quebrada (Méndez, Jackson, López y Jackson, 2005-06).

Un rasgo tafonómico relevante es la cobertura de roca gris/beige presente en prácticamente todas las piezas de microdiorita/diabasa. Se registró distribuida de manera homogénea sobre toda la superficie de cada pieza, cubriendo incluso zonas astilladas. Solo en algunos negativos y trituramientos se observa el color gris oscuro que caracteriza un corte fresco de esta litología.

A partir de esta observación podemos plantear que en todo el conjunto lítico de QQ no podríamos ver piezas con muchas coberturas de roca, como se observó en algunos especímenes recogidos del cauce de la quebrada Mal Paso, puesto que una cobertura de roca predominante podría estar sobrepuesta a cicatrices originadas en tiempos relativos distintos. Esta cobertura podría haber surgido en procesos posdepositacionales relacionados con la percolación de soluciones producto de la pedogénesis en las capas superiores (Dorn, 1998), o bien a partir de minerales arrastrados por el flujo constante de la quebrada, cuestión que se tiene que evaluar a futuro. Un dato relevante es que en los niveles holocénicos (miembros 4 y 6) de la matriz sedimentaria de QQ hay sucesivas intercalaciones de calizas y turbas (Núnez et al., 1994).

Otra cobertura de roca importante son las manchas de oxidación, las cuales se observaron en al menos el 61,43\% del conjunto de QQ. En nueve piezas esta cobertura se manifestó como improntas de raíces oxidadas, similar a lo que observamos en QSJ. Podemos sugerir que en QQ estas manifestaciones son una respuesta a la humedad en un ambiente lo suficientemente estable para permitir el desarrollo de vegetación, lo cual es esperable en ambientes perilacustres o palustres, lo cual se ha sugerido para los niveles Quereo I y II respectivamente (Núńez et al., 1994; Jackson et al., 2011). El alto contenido orgánico (turba) de la capa 37 en QSJ explicaría el mayor desarrollo de estas improntas de raíces en algunas piezas, lo cual sería una diferencia relevante respecto a los niveles contemporáneos de QQ. La menor cantidad de humedad en QQ también podría estar de acuerdo con la mejor preservación de material óseo, especialmente cuando lo comparamos con la pobre representación en QSJ (Méndez, 2010).

La relevancia de la humedad para el problema tafonómico abordado en esta investigación está en que la litología de la microdiorita/diabasa muestra un patrón de fractura "laminar" que se ve potenciado por su presencia. A través de la descripción unitaria de las piezas pudimos observar distintas fases en ciertos especímenes en los que el proceso tafonómico de oxidación de los planos de fractura interna contribuyó al desprendimiento de capas de roca, permitiendo el adelgazamiento natural de las piezas y la generación de bordes delgados y agudos. Si bien este proceso de generación de clastos laminares se observó parcialmente en algunos especímenes de la muestra natural de quebrada Mal Paso (p.e. Figura 5b), en el sitio Quebrada de Quereo se identifica con mucho mayor frecuencia debido a la litología de las rocas, las cuales exhiben debilidades estructurales y planos de fractura internos.

Estas observaciones nos permiten plantear una dinámica entre la meteorización química y física en los clastos de microdiorita/diabasa:

1. En primera instancia, se dio un proceso de oxidación de los componentes ferromagnesianos al interior de los planos de fractura internos, minerales que se caracterizan por una menor resistencia a la meteorización química (Goldich, 1938). Los nuevos compuestos van siendo liberados a través del proceso de disolución, potenciando a la vez la oxidación hasta romper los enlaces físicos que mantienen las fracturas cohesionadas, propiciando el desprendimiento de nuevos clastos laminares. Otros tipos de meteorización química pudieron haberse desarrollado en los planos de fractura internos de las piezas, puesto que en algunos casos vemos indicios de estos desprendimientos en ausencia de rastros de oxidación.

2. Luego, al disminuir el espesor de los clastos, estos se hacen cada vez más propensos a la fractura mecánica, incluso en las zonas donde este tipo de debilidades estructurales no existían 
originalmente. Además, como vimos en algunas piezas, estas fracturas laminares no siempre son paralelas entre sí, generándose planos oblicuos que en caso de desprenderse generarían bordes agudos (p.e. Figura 12a) que funcionarían como plataformas naturales. Estos nuevos bordes serían más propensos a la fractura, como lo señalan incluso los principios básicos de la talla lítica (Cotterell y Kaaminga, 1987; Whittaker, 1994).

3. Consideramos que este proceso habría ocurrido principalmente en una etapa preentierro, puesto que una vez sedimentados en el depósito, habría comenzado el desarrollo de la cobertura de roca predominante.

\section{Artefactos y pseudoartefactos del sitio Quebrada de Quereo}

Nuestro análisis ha permitido identificar dos procesos tafonómicos que permiten entender la variabilidad morfológica de las piezas del conjunto lítico de QQ:

\section{a. Generación de matrices por meteorización qui- mica y fractura mecánica por presión}

La fractura natural a partir de planos de debilidad interna en la microdiorita/diabasa propicia la generación de matrices con bordes agudos que, posteriormente, van siendo astillados a partir de fracturas generadas por presión, lo cual puede ocurrir en momentos de exposición a agentes de pisoteo, tanto en superficie como en una fase posdepositacional (Gifford-González, Damrosch, Damrosch, Pryor y Thunen, 1985; Nielsen, 1991; McBrearty, Bishop, Plummer, Dewar y Conard, 1998; Eren et al., 2011; De la Peña y Witelson, 2018). Las piezas donde estas fracturas se han producido en menor cantidad y solo en el extremo más delgado del borde son aquellas que poseen más atributos semejantes con instrumentos de corte (Núñez et al., 1983). En la Figura 11 se observa cómo este tipo de fracturas puede generar amplios desprendimientos, formando bordes agudos y delgados. En el caso expuesto en la Figura 11a, una gran fractura rebajó el espesor de la pieza, cortado en una fractura recta transversal. El espécimen se asemeja a un artefacto debido a que el borde astillado se opone a una zona roma de mayor espesor y sin cicatrices, lo cual puede ser interpretado como un "borde pasivo". El supuesto borde activo tiene siete cicatrices, con lo que se podría postular incluso un astillamiento por uso; sin embargo, algunas de estas extracciones tienen una apariencia "fresca" que sugiere una fractura más reciente que al momento de formación del depósito Pleistoceno.

La propensión natural de la microdiorita/diabasa a fracturarse en clastos de bordes relativamente agudos y delgados contribuye a que se generen piezas con plataformas naturales susceptibles a fracturas mecánicas en las zonas de menor resistencia (Warren, 1905; Méndez, 2010; McPherron et al., 2014). Al final de este proceso, los bordes adquieren ángulos más abruptos, en algunos casos casi rectos, generando piezas morfológicamente interpretables como aptas para el raspado o raído. La diferencia en el mayor o menor avance del astillamiento del borde podría tener relación con factores como la densidad del sustrato o la presencia de otros clastos que estén haciendo contacto entre sí, en tanto que ambos son factores que propician las fracturas por pisoteo o presión mecánica (McBrearty et al., 1998; Eren et al., 2011; De la Peña y Witelson, 2018).

En la Figura 12a podemos apreciar un avanzado estado de oxidación del borde desde donde se generaron astillamientos. Las fracturas internas en planos oblicuos son una señal de cómo la meteorización química actúa en estos planos de debilidad interna, favoreciendo la fractura mecánica. Al generarse bordes agudos con terminaciones delgadas, múltiples factores pueden explicar las fracturas de los nuevos bordes debilitados (Gifford-González et al., 1985; Luedtke, 1986; Nielsen, 1991; Andrefsky, 2013; McPherron et al., 2014).

El proceso de generación de matrices propensas a la fractura pudo ser generado a partir de desprendimientos individuales, o bien, desde varios de manera sucesiva. Esto último se puede sugerir para las piezas de las figuras 9c y 11b, en las cuales el borde delgado muestra desprendimientos de capas. Ambas piezas son un buen ejemplo del alto grado de astillamiento que puede presentar este tipo de clastos, con diez y más cicatrices bilaterales inclusive. 


\section{b. Fractura por percusión de bordes naturales}

Dada la combinación del ambiente aluvial de depositación y el tipo de materias primas representadas en el conjunto de $\mathrm{QQ}$, proponemos que sus piezas fueron afectadas por eventos de percusión circunstanciales, lo cual es particularmente notorio en las piezas del denominado "estrato negro" (Núñez et al., 1994), en donde se habrían formado algunos pseudoartefactos por esta causa.

En el caso del espécimen de las figuras 9a y 9b, el borde astillado de la pieza interrumpe la cobertura de roca beige-gris con marcas de oxidación, lo que permite inferir un origen más reciente para estas extracciones. Otro caso es el de la pieza de las figuras $10 \mathrm{a}$ y $10 \mathrm{~b}$, en donde se observa una especie de muesca conformada por dos astillamientos grandes, pero también con una apariencia "fresca", libre de la cobertura de roca predominante en el sitio.

El origen relativamente reciente de los negativos de estas piezas se sostiene al comparar con otros especímenes del conjunto que presentan la misma cobertura de roca gris-beige con marcas de oxidación homogéneamente distribuida en la pieza, incluyendo la zona astillada (ver Figuras $7 a-f$ y $12 b$ ). Sería esperable que todas las piezas de los niveles del Pleistoceno estén completamente afectadas por la cobertura de roca típica del conjunto, lo cual no se cumple en las piezas con percusión circunstancial en tiempos relativamente recientes.

Un ejemplo de lo que podríamos esperar para una pieza cuyas cicatrices del borde se remontan al Pleistoceno terminal lo podemos ver en varios ejemplares de Santa Julia, en donde las improntas de raíces oxidadas se superponen a las zonas astilladas de los bordes, sin ser interrumpidas por ningún negativo. Esta condición indica que su desarrollo fue posterior al ingreso de las piezas al contexto arqueológico (ver Figura 6).

Para que se produjera una muesca intencional, como la que supuestamente estaría presente en la pieza de las figuras 10a y 10b, debiéramos esperar que el instrumento no presente solo los astillamientos que conformaron el borde, sino también algún tipo de retoque superpuesto o algún trituramien- to provocado por su uso, lo cual no se observa en este espécimen. Esto contrasta con algunas piezas de QSJ, en que pequeños gestos técnicos permiten identificar acciones intencionadas como, por ejemplo, una lasca con múltiples astillamientos pequeńos en dos bordes convergentes que forman una "punta destacada" (Méndez, 2010).

La percusión aislada es bastante común si se consideran todos los bordes de las piezas, no solo aquellos acá definidos como activos. En otros especímenes del conjunto se observan percusiones aisladas en los bordes que conformarían una eventual zona pasiva (p.e., Figura 7e).

En definitiva, bastan solo algunos eventos aislados de percusión en el proceso previo a la depositación de la pieza para producir este rasgo. En el caso de la pieza de las Figuras 9a y 9b, se necesita un mayor tiempo de exposición a alguna energía mecánica que pueda producir percusiones sucesivas, aunque la poca profundidad de los negativos podría estar revelando algún tipo de fractura por presión, quizá por contacto con otras rocas (McBrearty et al., 1998; Eren et al., 2011).

\section{Lascas del conjunto lítico de Quereo}

Nuestro análisis tafonómico y tecnológico no nos permitió descartar un origen antropogénico respecto a dos lascas del conjunto lítico de QQ. Estas piezas, o bien no tienen bulbo de percusión $\mathrm{u}$ otro rasgo que indique la orientación de la fuerza en la extracción o, si los presentan, no está clara su procedencia respecto a los niveles del Pleistoceno. Una de estas lascas proviene del nivel Quereo II (Núñez et al., 1987), tiene el anverso sin corteza, su talón es plano, y aunque no exhibe bulbo de percusión tiene ondas bastante marcadas (ver Figura 8d). Además, muestra una cobertura de roca café levemente desarrollada y un borde con trituramiento. En la otra pieza se observa una probable zona bulbar y un talón plano, mostrando una cobertura de roca homogénea que no permite distinguir con toda seguridad la cara ventral de la dorsal (ver Figura 8f).

En ninguno de estos casos observamos rasgos irrefutablemente antropogénicos, como podrían ser restos de preparación de la plataforma o aristas complejas 
(Andrefsky, 2013). Además, al no poder distinguir con seguridad un anverso y un reverso, sus atributos no permiten distinguir si la zona proximal efectivamente corresponde a un talón plano o solo a una superficie plana remanente de la matriz original en la cual no se efectuó la percusión. Creemos que en este caso un análisis macroscópico no basta para disipar la ambigüedad antropogénica en estas piezas.

\section{Conclusión}

El análisis tafonómico aplicado al conjunto lítico de QQ nos permite sostener que buena parte de las características de las piezas puede explicarse como el producto del proceso de meteorización de las rocas, en el cual participan tanto agentes externos relacionados con el ambiente depositacional de la matriz sedimentaria como aspectos litológicos relacionados con el tipo de fractura y los planos de debilidad internos de la microdiorita/diabasa. Con esto, planteamos que, con excepción de dos lascas de potencial factura antropogénica, las piezas líticas de los niveles del Pleistoceno de Quebrada de Quereo corresponderían a pseudoartefactos.

En nuestro trabajo no identificamos rasgos que nos permitieran sugerir alguna preparación intencional para la obtención de matrices. Más bien, poniendo el foco en los rasgos tafonómicos potenciales, pudimos identificar un tipo de fractura natural en la microdiorita/diabasa que produce matrices con bordes agudos y delgados sin la necesidad de percusión. La alta presencia de una cobertura de roca de color gris a beige nos permite calificar como recientes todas las cicatrices en los bordes de las piezas libres de esta cobertura. Esto incluye prácticamente todos los negativos atribuibles a fuerzas de percusión y la gran mayoría de los astillamientos provocados por presión. Además, no identificamos gestos técnicos que revelen alguna intencionalidad para formatizar rasgos morfológicos concretos, como podría esperarse, por ejemplo, en las muescas de algunas piezas. Consideramos que solo en el caso de dos lascas no pudimos disipar la ambigüedad antropogénica debido a la presencia de algunos rasgos que, si bien pueden ser considerados como tecnológicos, no son determinantes como para zanjar el problema.
Nuestras conclusiones deben ser matizadas en función de las limitaciones del estudio que hemos desarrollado. El registro de atributos tafonómicos como niveles de abrasión, coberturas de roca, manchas de oxidación o meteorización de los bordes está aún en un nivel cualitativo. Lo mismo podemos decir de la identificación petrológica, en tanto que las piezas identificadas como de "grano medio" o microdioritas/diabasas, si bien se observa una homogeneidad importante, hay algunas variantes en color y textura en las que nuestras categorías no ahondan.

Por otra parte, este trabajo no tuvo un diseño experimental que buscara replicar las condiciones exactas que generaron el conjunto lítico del sitio arqueológico analizado, como se ha hecho en otros trabajos con problemáticas similares (p.e., McPherron et al., 2014; De la Peńa y Witelson, 2018). Nuestro diseńo apuntó a recoger análogos de campo que permitieran representar distintos grados de equifinalidad en un ambiente depositacional similar al sitio Quebrada de Quereo, buscando identificar agentes de meteorización no solo del tipo mecánico (como los agentes del pisoteo), los cuales pueden ser replicados en el laboratorio, sino que también ejemplos de meteorización química, los que solo pueden encontrarse en rocas que interactúan con el medio ambiente en tiempos prolongados.

A modo de conclusión, los análisis conducidos sugieren que no hay que juzgar un sitio como una unidad donde se acepte o rechace toda su evidencia por completo, sino como una fuente de distintas líneas de evidencia para ponderarlas independientemente. Por ejemplo, al ser sometidos a un análisis tafonómico, una importante proporción de las marcas de los restos óseos de QQ pudo ser explicada por procesos diferentes a la intervención humana (López et al., 2004). Sin embargo, algunos especímenes han mostrado huellas de lascados sistemáticos, tanto en el sitio mismo como en conjuntos superficiales del área inmediata (Jackson et al., 2004; López, 2007). Es difícil en este punto descartar de plano la presencia humana en QQ; más bien debiéramos considerarla como ambigua y tenue, con atributos pro y contra y con un gran potencial, en tanto estamos seguros de que hubo humanos transitando en la zona durante su formación (Méndez, 2015). En Sudamérica son varios los sitios cuyos conjuntos presentan rasgos de origen antropogénico 
débiles y vagamente sustentados por atributos tecnológicos definitivos y que podrían beneficiarse de investigaciones con enfoque tafonómico (p.e., Guidon y Arnaud, 1991; Guidon et al., 1996; Guidon, 2008; Boëda et al., 2014; Fariña et al., 2014a).

La metodología acá propuesta busca acortar la "zona intermedia" en el continuo morfológico natural-antropogénico. A través de la comparación a escala local con muestras de rocas con fracturas claramente naturales y la identificación de rasgos tafonómicos en un conjunto lítico con claras señales antropogénicas en un contexto depositacional análogo, se aplicó un análisis a un conjunto de alta relevancia. Estas metodologías, si bien propuestas hace décadas, no suelen ser utilizadas por el hecho de no reconocerse en el problema de la ambigüedad antropogénica un impedimento para la discusión de la evidencia a nivel de sitios y a nivel regional (Borrero, 2016).

En este sentido, cabe preguntarse, ¿hasta qué punto es tolerable la ambigüedad antropogénica para la interpretación de un sitio? En este trabajo hemos planteado que es necesario ofrecer una explicación tafonómica para confrontarla como hipótesis a otras alternativas para explicar el origen de piezas dudosas, sin descartar esta posibilidad de manera injustificada, como una manera de disminuir el peso de la ambigüedad antropogénica en la interpretación de un sitio arqueológico.

\section{Agradecimientos}

Trabajo financiado por ANID-FONDECYT 1170408. Una versión preliminar fue presentada en el undécimo ISKM 2017, Buenos Aires, Argentina. Agradecemos a Ángel Durán, director del Museo Arqueológico de La Serena por el acceso a la colección del sitio Quebrada de Quereo. La colección del sitio Quebrada Santa Julia está curada en la Universidad de Chile. Agradecemos a la familia Matte por las facilidades para la excavación de quebrada Santa Julia y los muestreos en quebrada Mal Paso. Agradecemos a Donald Jackson por su guía en este trabajo, que fue producto de la tesis de pregrado del primer autor, y al Dr. Lautaro Núńez, quien guio la tesis doctoral del segundo autor y ha compartido gentilmente sus ideas respecto a los conjuntos líticos del sitio Quebrada de Quereo.

\section{Referencias citadas}

Andrefsky, W. (2005). Lithics: macroscopic approaches to analysis. New York: Cambridge University Press.

Andrefsky, W. (2013). Fingerprinting flake production and damage processes: Toward identifying human artifact characteristics. En Graf, K., Ketron, C. y Waters, M. (Eds.). Paleoamerican Odyssey (pp. 415-428). Texas: Center for the Study of the First Americans, Texas A\&M University.

Ascher, R. y Ascher, M. (1965). Recognizing the emergence of man. Science, 147, 3655.

Balirán, C. (2014). Trampling, taphonomy, and experiments with lithic artifacts in the southeastern Baguales Range (Santa Cruz, Argentina). Intersecciones en Antropología, Special Issue, 1, 85-95.

Bate, F. (1971). Material lítico: metodología de clasificación. Noticiario Mensual del Museo Nacional de Historia Natural, 181-182, 3-24.

Boëda, E., Clemente-Conte, I., Fontugne, M., Lahaye, C., Pino, M., Felice, G. ... Douville, E. (2014). A new late Pleistocene archaeological sequence in South America: The Vale da Pedra Furada (Piauí, Brazil). Antiquity, 88, $927-41$.

Borrazzo, K. (2006). Tafonomía lítica en dunas: una propuesta para el análisis de los artefactos líticos. Intersecciones en Antropología, 7, 247- 261.

Borrazzo, K. (2011). Tafonomía lítica y pseudoartefactos: el caso de la península El Páramo (Tierra del Fuego, Argentina). Intersecciones en Antropología, 12, 155-167.

Borrazzo, K. (2016). Lithic taphonomy in desert environments: Contributions from Fuego-Patagonia (Southern South America). Quaternary International, 422, 19-28.

Borrero, L. (2016). Ambiguity and debates on the early peopling of South America. PaleoAmerica. DOI: $10.1080 / 20555563.2015 .1136498$

Burroni, D., Donahue, R. y Pollard, A. (2002). The surface alteration features of flint artefacts as a record of environmental processes. Journal of Archaeological Science, 29, $1277-1287$. 
Cecioni, G. y Westermann, C. (1968). The Triassic-Jurassic marine transition of coastal central Chile. Pacific Geolo$g y, 1,41-75$.

Cotterell, B. y Kaaminga, J. (1987). The formation of flakes. American Antiquity, 52, 675-708.

De la Peña, P. y Witelson, D. (2018). Trampling vs. retouch in a lithic assemblage: a case study from a Middle Stone Age site, Steenbokfontein 9KR (Limpopo, South Africa). Journal of Field Archaeology, 43(7), 522-537.

Dorn, R. (1998). Rock coatings. Amsterdam: Elsevier.

Ellen R. y Muthana A. (2010). Classifying 'eoliths': how cultural cognition featured in arguments surrounding claims for the earliest human artefacts as these developed between 1880 and 1900. Journal of Cognition and Culture, 10, 341-375.

Eren, M., Boehm A., Morgan B., Anderson R., y Andrews B. (2011). Flake stone taphonomy: a controlled experimental study of the effects of sediment consolidation on flake edge morphology. Journal of Taphonomy, 9, 201-17.

Fariña, R., Tambusso, A., Varela, L., Czerwonogora, A., Di Giacomo, M., Musso, M. ... Gascue, A. (2014a). Arroyo del Vizcaíno, Uruguay: A fossil-rich 30-ka-old megafaunal locality with cut-marked bones. Proceedings of the Royal Society B, 281, 2013-2211.

Fariña R., Tambusso, P., Varela, L., Di Giacomo, M., Musso, M., Gascue, A. ... Bracco, R. (2014b). Among others, cut-marks are archaeological evidence: reply to 'Archaeological evidences are still missing: a comment on Fariña et al. Arroyo del Vizcaíno Site, Uruguay' by Suárez et al. Proceedings of the Royal Society B, 281, 20141637. DOI: 10.1098/rspb.2014.1637.

Fiedel, S. (2017). Did monkeys make the pre-Clovis pebble tools of Northeastern Brazil? PaleoAmerica, 3(1), 6-12.

Garvey, R. y Mena, F. (2016). Confronting complexities of artifact-geofact debates: re-analysis of a coarse volcanic rock assemblage from Chilean $\mathrm{Pa}-$ tagonia. Lithic Technology, 41(2), 114-129. DOI: 10.1080/01977261.2016.1152023.

Gifford-González, D., Damrosch, D., Damrosch, D., Pryor, J. y Thunen, R. (1985). The third dimension in site structure: an experiment in trampling and vertical dispersal. American Antiquity, 50, 803-818.

Gillespie, J., Tupakka, S. y Cluney, C. (2004). Distinguishing between naturally and culturally flaked cobbles: a test case from Alberta, Canada. Geoarchaeology: An International Journal, 19, 615-633.

Goldberg, P. y Macphail, R. (2006). Practical and theoretical geoarchaeology. Malden, Oxford, Carlton, UK: Blackwell Publishing.

Goldich, S. (1938). A study in rock-weathering. The Journal of Geology, 46, 17-58.

Guidon, N. (2008). Pedra Furada: A revision. Fundhamentos VII.

Guidon, N. y Arnaud, B. (1991). The chronology of the New World: two faces of one reality. World Archaeology, 23, 167-178.

Guidon, N., Pessis, A., Parenti, F., Fontugue, M. y Guérin, C. (1996). Nature and age of the deposits in Pedra Furada, Brazil: reply to Meltzer, Adovasio y Dillehay. Antiquity, 70, 408-21.

Haynes, C. (1973). The Calico site: artifacts or geofacts? Science, 181, 305-310.

Hiscock, P. (1985). The need for a taphonomic perspective in stone artefact analysis. Queensland Archaeological Research, 2, 82-95.

Hosfield, R. y Chambers, C. (2003). Flake modifications during fluvial transportation: three cautionary tales. Lithics: The Newsletter of the Lithic Studies Society, 24, 57-65.

Inizan, M., Reduron-Ballinger, M., Roche, H. y Tixier, J. (1999). Technologie de la pierre taillée. Meudon, Francia: CREP.

Jackson, D., Méndez, C. y De Souza, P. (2004). Poblamiento Paleoindio en el Norte-Centro de Chile: evidencias, problemas y perspectivas de estudio. Complutum, 15, $165-176$.

Jackson, D., Méndez, C., Seguel, R., Maldonado, A. y Vargas, G. (2007). Initial occupation of the Pacific Coast of Chile during late Pleistocene times. Current Anthropology, 48(5), 725-731. 
Jackson, D., Méndez, C., Núñez, L. y Jackson, D. (2011). Procesamiento de fauna extinta durante la transición Pleistoceno-Holoceno en el centro-norte de Chile. Boletin de Arqueología PUCP, 15, 315-336.

López, P. (2007). Tafonomía de los mamíferos extintos del pleistoceno tardío de la costa meridional del semiárido de Chile (IV región - $32^{\circ}$ latitudes): alcances culturales y paleoecológicos. Chungara. Revista de Antropología Chilena, 39(1), 69-86.

López, P., Labarca, R. y Núñez, L. (2004). Nivel Quereo I. Una discusión acerca del poblamiento temprano en la Provincia del Choapa. Werken, 5, 15-20.

Lopinot N. y Ray, J. (2007). Trampling experiments in the search for the earliest Americans. American Antiquity, 72(4), 771-782.

Lubinski P., Terry, K., y McCutcheon, P. (2014). Comparative methods for distinguishing flakes from geofacts: a case study from the Wenas Creek Mammoth site. Journal of Archaeological Science, 52, 308-320.

Luebert, F. y Pliscoff, P. (2006). Sinopsis bioclimática y vegetacional de Chile. Santiago: Universitaria.

Luetdke, B. (1986). An experiment in natural fracture. Lithic Technology, 15, 55-60.

Maldonado, A., Méndez, C., Ugalde, P., Jackson, D., Seguel, R. y Latorre, C. (2010). Early Holocene climate change and human occupation along the semiarid coast of north-central Chile. Journal of Quaternary Science, 25(6), 985-988

McBrearty, S., Bishop, L., Plummer, T., Dewar, R. y Conard N. (1998). Tools underfoot: human trampling as an agent of lithic artifact edge modification. American Antiquity, 63, 108-129.

McPherron S., Braun, D., Dogandzic T., Archer, W., Desta, D. y Lin, S. (2014). An experimental assessment of the influences on edge damage to lithic artifacts: a consideration of edge angle, substrate grain size, raw material properties, and exposed face. Journal of Archaeological Science, 49, 70-82.

Méndez, C. (2004). Una sociedad de cazadores recolectores en movimiento durante la primera mitad del Holoceno tardio en Los Vilos. Tesis para optar al grado de Magíster en An- tropología, mención Arqueología. Universidad Católica del Norte, Chile.

Méndez, C. (2010). Tecnología lítica en el poblamiento pleistoceno terminal del centro de Chile. Organización, gestos y saberes. Tesis para optar al grado de Doctor en Antropología, mención Arqueología. Universidad Católica del Norte, Chile.

Méndez, C. (2015). Los primeros andinos. Tecnología litica de los habitantes de Chile trece mil años atrás. Lima: Fondo Editorial de la Pontificia Universidad Católica del Perú, Colección Estudios Andinos.

Méndez C. y Jackson, D. (2015). Terminal Pleistocene lithic technology and use of space in Central Chile. Chungara. Revista de Antropología Chilena, 47(1), 53-65.

Méndez, C., Jackson, D., y Seguel, R. (2004). Narrowing the spatial range of megafaunal distributions on the Semiarid coast of Chile. Current Research in the Pleistocene, 21, 109-110.

Méndez, C., Jackson, D., López, P. y Jackson, D. (2005-6). Tan lejos, tan cerca: de sitios paleoindios y depósitos secundarios. Intervenciones arqueológicas en el nivel II del yacimiento pleistocénico "Las Monedas". Revista Chilena de Antropología, 18, 135-153.

Nielsen, A. (1991). Trampling the archaeological record: an experimental study. American Antiquity, 56, 483-503.

Núñez, L., Varela, J. y Casamiquela, R. (1983). Ocupación Paleoindio en Quereo. Antofagasta: Universidad del Norte, Chile.

Núñez, L., Varela, J. y Casamiquela, R. (1987). Ocupación paleoindia en el centro norte de Chile: adaptación circunlacustre en las tierras bajas. Estudios Atacameños, 8, 142-185.

Núñez, L., Varela, J., Casamiquela, R. y Villagrán, C. (1994). Reconstrucción multidisciplinaria de la ocupación prehistórica de Quereo, centro de Chile. Latin American Antiquity, 5(2), 99-118.

Oakley, K. (1968). Man the tool-maker. Chicago, IL: The University of Chicago Press.

O'Connor, A. (2007). Finding time for the old Stone Age. A history of palaeolithic archaeology and quaternary geology in Britain, 1860-1960. Oxford, UK: Oxford University Press. 
Ortega, C., Vargas, G., Rutllant, J., Jackson, D., Méndez, C. (2012). Major hydrological regime change along the semiarid western coast of South America during the early Holocene. Quaternary Research, 78, 513-527.

Patterson, L. (1983). Criteria for determining the attributes of man-made lithics. Journal of Field Archaeology, 10(3), 297-307.

Peacock, E. (1991). Distinguishing between artifacts and geofacts: A test case from Eastern England. Journal of Field Archaeology, 18(3), 345-361.

Petraglia, M. y Potts, R. (1994). Water flow and the formation of Early Pleistocene artifact sites in Olduvai Gorge, Tanzania. Journal of Anthropological Archaeology, 13, 228-254.

Prentiss, A., Walsh, M., Barnett, K., Murphy, M-M. y Kuenstle, J. (2015). The coarse volcanic rock industry at the Rio Ibañez 6 west site, Chilean Patagonia. Lithic Technology, 40(2), 112-127

Proffitt T., Luncz, L., Falótico, T., Ottoni, E., De la Torre, I. y Haslam, M. (2016). Wild monkeys flake stone tools. Nature, 539, 85-88.

Rivano, S. y Sepúlveda, P. (1991). Hoja Illapel. Región de Coquimbo. Santiago: Sernageomin.

Schiffer, M. (1983). Toward the identification of formation processes. American Antiquity, 48(4), 675-706.

Schulz, H-P. (2010). The Susiluola cave site in western Finland. Evidence of the northernmost Middle palaeolithic settlement in Europe. Studia Archeologiczne, XLI.

Stein, J. (1987). Deposits for archaeologists. En Schiffer, M. (Ed.). Advances in Archaeological Method and Theory (pp. 337-395). San Diego, CA: Academic Press.
Suárez, R., Borrero, L., Borrazzo, K., Ubilla, M., Martínez, S. y Perea, D. (2014). Archaeological evidences are still missing: a comment on Farińa et al. Arroyo del Vizcaíno Site, Uruguay. Proceedings of the Royal Society B, 281, 20140449.

Ugalde, P., Santoro, C., Gayo, E., Latorre, C., Maldonado, S., De Pol-Holz, R. y Jackson, D. (2015). How do surficial lithic assemblages weather in arid environments? A case study from the Atacama Desert, Northern Chile. Geoarchaeology, 30, 352-368.

Varela, J. (1981). Geología del Cuaternario del área de Los Vilos - Ensenada El Negro (IV Región) y su relación con la existencia del bosque "relicto" de Quebrada Quereo. Comunicaciones, 33, 17-30.

Vicente, J. (1974). Example de "volcanisme initial euliminare". Les complexes albitophyriques neotriassiques et Jurassiques du secteur côtier des Andes Meridionales (32 $-33^{\circ}$ Lat. Sud). En González, O. (Ed.). Simposium on Andean Volcanology and Chemical of the Earth's Interior, 267-329. Santiago.

Warren, S. H. (1905). On the origin of 'eolithic' flints by natural causes, especially by the foundering of drifts. Man, 5, 337-364.

Weitzel, C., Borrazzo, K., Ceraso, A. y Balirán, C. (2014). Trampling fragmentation potential of lithic artifacts: an experimental approach. Intersecciones en Antropología, Special Issue, 1, 97-110.

Whittaker, J. (1994). Flintknapping: Making and understanding stone tools. Texas, TX: University of Texas Press. 